\title{
Biomass-derived carbon materials with structural diversities and their applications in energy storage
}

\author{
Lili Jiang ${ }^{1,2}$, Lizhi Sheng ${ }^{2}$ and Zhuangjun Fan ${ }^{2 *}$
}

\begin{abstract}
Currently, carbon materials, such as graphene, carbon nanotubes, activated carbon, porous carbon, have been successfully applied in energy storage area by taking advantage of their structural and functional diversity. However, the development of advanced science and technology has spurred demands for green and sustainable energy storage materials. Biomass-derived carbon, as a type of electrode materials, has attracted much attention because of its structural diversities, adjustable physical/chemical properties, environmental friendliness and considerable economic value. Because the nature contributes the biomass with bizarre microstructures, the biomass-derived carbon materials also show naturally structural diversities, such as OD spherical, 1D fibrous, 2D lamellar and 3D spatial structures. In this review, the structure design of biomass-derived carbon materials for energy storage is presented. The effects of structural diversity, porosity and surface heteroatom doping of biomass-derived carbon materials in supercapacitors, lithium-ion batteries and sodium-ion batteries are discussed in detail. In addition, the new trends and challenges in biomass-derived carbon materials have also been proposed for further rational design of biomass-derived carbon materials for energy storage.
\end{abstract}

Keywords: biomass-derived carbon materials, supercapacitors, lithium-ion batteries, sodium-ion batteries

\section{INTRODUCTION}

With the depleting energy and deteriorating environment arising from the excessive use of fossil fuels, some researchers are driving in the development of environmentfriendly renewable energy, such as solar, wind, hydro, and biomass energy $[1,2]$. Consequently, the exploitation of high power energy storage devices is important for elec- tric vehicles and consumer electronics around the world [3]. Among various energy storage devices, supercapacitors have higher power density and cycling stability [4-7], while lithium- and sodium-ion batteries possess relatively large specific capacity and high working voltage [8-10]. However, the performances of the energy storage devices primarily depend on the electrode materials with ideal structural design, simple preparation process, specific properties, abundant resources, low-cost and environmental friendliness.

Among the exploited energy materials, carbon materials have attracted a great deal of attention as the electrode materials due to their high electronic conductivity, adjustable microstructure and excellent stability $[9,11,12]$. In particular, graphene or carbon nanotube, as a rising star in carbon materials, exhibits specific structure and exceptional physicochemical properties [13-16], nevertheless, their preparation process is usually complicated $[17,18]$. For example, high quality graphene is commonly prepared through chemical vapor deposition using fossil fuel-based molecules as precursors (such as methane, acetylene, ethylene), which suffers from high cost and very low yield [19]. Although the preparation of graphene by classical Hummer's method has been achieved in small batches production, using the strong acid and oxidation agents will bring environmental pollution [18]. Thus, it is significant to seek green, efficient, low-cost preparation method and renewable raw materials for carbon materials. As carbon-rich precursors, biomass has been considered as a promising candidate in preparation of functional carbon materials because they are bountiful, renewable, non-toxic and low cost [20]. Importantly, the nature usually gives biomass a variety of microstructures,

${ }^{1}$ College of Materials Science and Engineering, Jilin Institute of Chemical Technology, Jilin 132022, China

${ }^{2}$ Key Laboratory of Superlight Materials and Surface Technology, Ministry of Education, College of Material Science and Chemical Engineering, Harbin Engineering University, Harbin 150001, China

*Corresponding author (email: fanzhj666@163.com) 


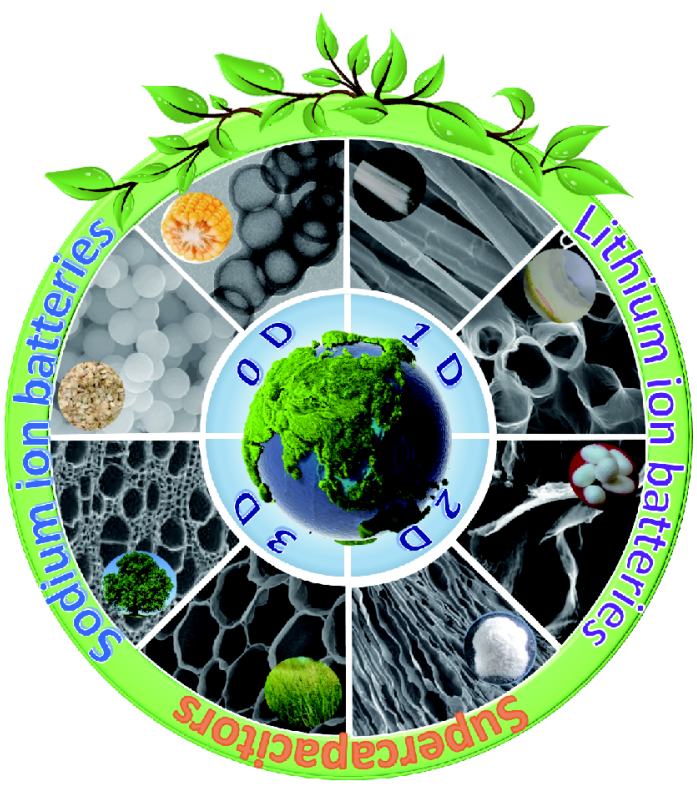

Figure 1 An overview of structural diversities of biomass-derived carbon materials and the applications in supercapacitors, lithium- and sodium-ion batteries.

which could be used as precursors for preparing carbon materials with specific structures. Miraculously, biomassderived carbon materials can also inherit or evolve special microstructures including $0 \mathrm{D}$ spherical structure $[21,22]$, 1D fibrous structure [23,24], 2D lamellar structure $[25,26]$ and $3 \mathrm{D}$ skeleton structure [27-29], as shown in Fig. 1. So far, a series of novel biomass-derived carbon materials have been made by pyrolysis, activation, or hydrothermal carbonization, such as plants, animals, domestic waste and biomacromolecules.

Recently, the research of biomass-based energy storage becomes a burgeoning trend to reduce the growing consumption of non-renewable resources. Moreover, the biomass-derived carbon electrodes have many advantages, such as high specific surface area (SSA), welldefined pore size distribution, excellent electric conductivity and easily modified surface chemistry [30,31]. On the one hand, numerous biomass-derived carbon materials with naturally porous or hierarchical structures of the biomass or created pores deriving from activation facilitate the electrolyte penetration and shorten the ion diffusion distance $[32,33]$. On the other hand, the defects including vacancies, edges and heteroatoms can be formed during the biomass pyrolysis process [31]. Most natural biomass materials contain nitrogen and/or sulfur, which can be doped by heteroatoms, resulting in increasing electric conductivity and extra active sites $[34,35]$. More importantly, a large amount of biomass material is recycled from the daily or agricultural wastes, meaning an effective, cheap and environment-friendly process of the electrode materials. In this review, a brief summary of recent research progress on the well-design of biomass-derived carbon materials for energy storage applications is presented, mainly including structure diversity, heteroatom modification and preparation of biomass-derived carbon as well as an emphasis on their applications in supercapacitors, lithium- and sodium-ion batteries. In addition, new trends in biomass-derived carbon materials development have also been proposed.

\section{STRUCTURAL DIVERSITIES OF BIOMASS- DERIVED CARBONS}

Among the energy storage materials, biomass-derived carbon materials have attracted intensive interest not only because they are abundant and environment-friendly, but also because they have specific morphologies and adjustable porosity. Briefly, biomass-derived carbon materials normally can be obtained by pyrolysis of natural or waste biomass materials. Importantly, the parameters of optimum pore size distribution and surface area of the electrode materials ultimately detemine the performance of energy storage devices. In particular, producing morphology-controllable materials with structural specificity, complexity and unique functionality is challenging for energy storage applications [36].

\section{Specific morphologies}

In nature, biomass materials usually exhibit quite broad diversity in macrostructures. Miraculously, biomass-derived carbon materials can also be inherited or evolved special microstructures, such as spherical, fibrous, sheet, tubular, rod-like, graphene-like materials.

\section{Spherical structure}

It is well-known that most of carbon spheres obtained from sugar sources (sucrose and glucose) hydrothermally with a smooth surface [37-41] (Fig. 2a, b). In addition to sugar, carbon spheres derived from $\mathrm{N}$-rich oatmeal through hydrothermal and subsequent carbonization process were reported by Yan et al. [22], exhibiting smooth surface with an average diameter of about $2 \mu \mathrm{m}$ (Fig. 2c). The size of the biomass-derived carbon spheres is changed from $200-400 \mathrm{~nm}$ to $1-2 \mu \mathrm{m}$ [42]. Furthermore, Gaddam et al. [21] reported that smaller carbon spheres were obtained from coconut oil via flame deposition (Fig. 2d). The obtained carbons spheres show particle size ranging from $40-50 \mathrm{~nm}$, and dense structure with a SSA of $56 \mathrm{~m}^{2} \mathrm{~g}^{-1}$, which is beneficial to the ap- 


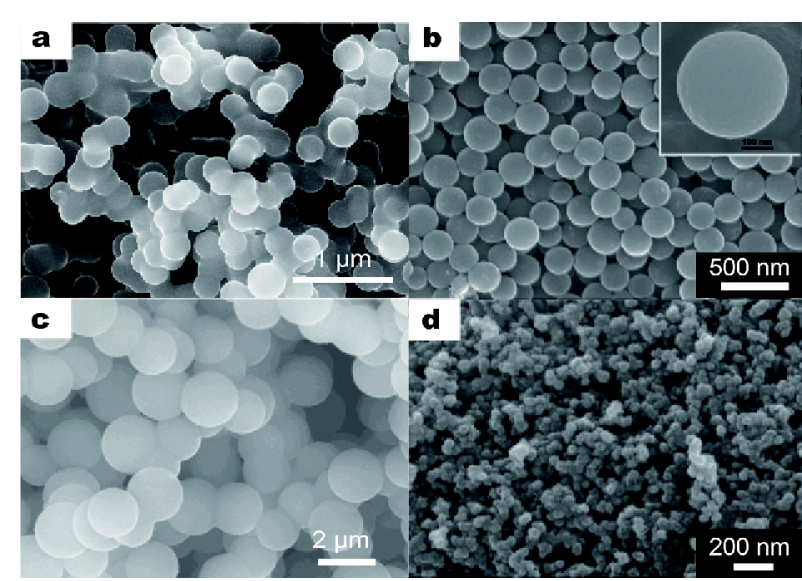

Figure 2 (a) SEM image of glucose-based CMs. Reprinted with permission from Ref. [39] Copyright 2016, Elsevier. (b) SEM image of glucose-based carbon nanospheres. Reprinted with permission from Ref. [40] Copyright 2014, Elsevier. (c) SEM image of oatmeal-based N-doped CMs (NCSs-500). Reprinted with permission from Ref. [22] Copyright 2016, Elsevier. (d) SEM image of coconut oil-based carbon nanoparticles (CNPs). Reprinted with permission from Ref. [21], Copyright 2016, Elsevier.

plication of sodium- and lithium-ion batteries. Moreover, these biomass-derived carbon spheres, especially for sugar-based derived carbon spheres, can also be used as templates or substrates for the synthesis of high-capacity active materials [40,43].

Most of the sugar-based carbon spheres, synthesized by the hydrothermal method, has solid sphere structure which is not conducive to the transport and diffusion of the electrolyte ions inside the electrode materials. Therefore, porous and hollow carbon spheres have been received widespread attention [44-47]. Gao et al. [48] synthesized $\mathrm{N}$-doped porous carbon spheres (N-CSs) with high SSAs $\left(2105.9 \mathrm{~m}^{2} \mathrm{~g}^{-1}\right)$ and high porosity (1.14 $\mathrm{cm}^{3} \mathrm{~g}^{-1}$ ) by fermented rice as starting materials. The highly porous loosely-packed network in carbon spheres is attributed to chemical activation using $\mathrm{ZnCl}_{2}$, which can improve the electrolyte ion transfer. Duan et al. [49] prepared $\mathrm{N}$-doped carbon microspheres (CMs) by pyrolyzing the chitin derived from discarded seafood waste (crab and shrimp shell). The CMs were composed of robust cross-linked nanofibers and displayed interconnected nanofibrous framework architecture (Fig. 3). Such a unique structure brings in special performances, such as excellent elasticity, compressibility and recoverability. As a result, these porous structures inside the carbon spheres form 3D interconnect pores with a large surface area, which can provide good charge accommodation and be able to endure high current loads.

On the other hand, to introduce porosity in carbons,
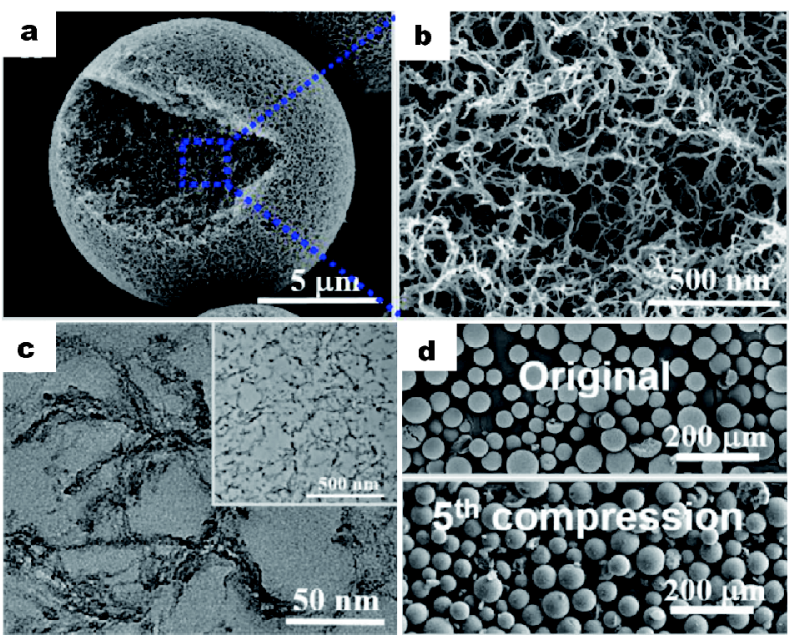

Figure 3 Structure characterization of the N-doped nanofibrous CMs (NCM900): SEM images (a, b) of the CMs; TEM image (c) of the CMs (insert: the selected area diffraction pattern); SEM images (d) of the CMs before and after 5 cyclic $75 \%$ strain compression tests, respectively. Reprinted with permission from Ref. [49], Copyright 2016, Elsevier.

some researchers used biomass as carbon source and removable template to design hollow carbon spheres. The unique hollow structure may boost mass transport by high surface area and short diffusion distance. Falco et al. [50] employed hemicellulose hydrolysis products derived from spruce or corncob to cover silica nanoparticle hardtemplating and followed by removal of the template to obtain hollow carbon spheres (Fig. 4a, b). Tang et al. $[51,52]$ successfully prepared hollow carbon spheres with a diameter of $\sim 100 \mathrm{~nm}$ and amorphous carbon shell with a thickness of $12 \mathrm{~nm}$ by hydrothermal carbonization of glucose with latex templates (Fig. 4c, d). After thermal treatment, the template is removed to produce thin carbon shell to shorten ion diffusion distance.

Except for additional templates, some biomass materials themselves can act as template to produce hollow carbon spheres. For instance, spores with core/shell structure are natural reservoir of carbon sources. Jin et al. [53] fabricated porous hollow carbon spheres by hightemperature carbonization and activation using various spores (Lycopodium clavatum, Ganodorma lucidum and Lycopodium annotinum spores) as carbon precursors and self-templates (Fig. 5a). The abundant and easily available carbon sources of spores allow for mass production of hollow carbon spheres, which almost faultlessly inherit the distinctive nano-architectures of spores, presenting super-high SSA $\left(3053 \mathrm{~m}^{2} \mathrm{~g}^{-1}\right)$ and hierarchically porous structure. In addition, Wei et al. [54] reported an ecofriendly strategy to prepare three-dimensional inter- 

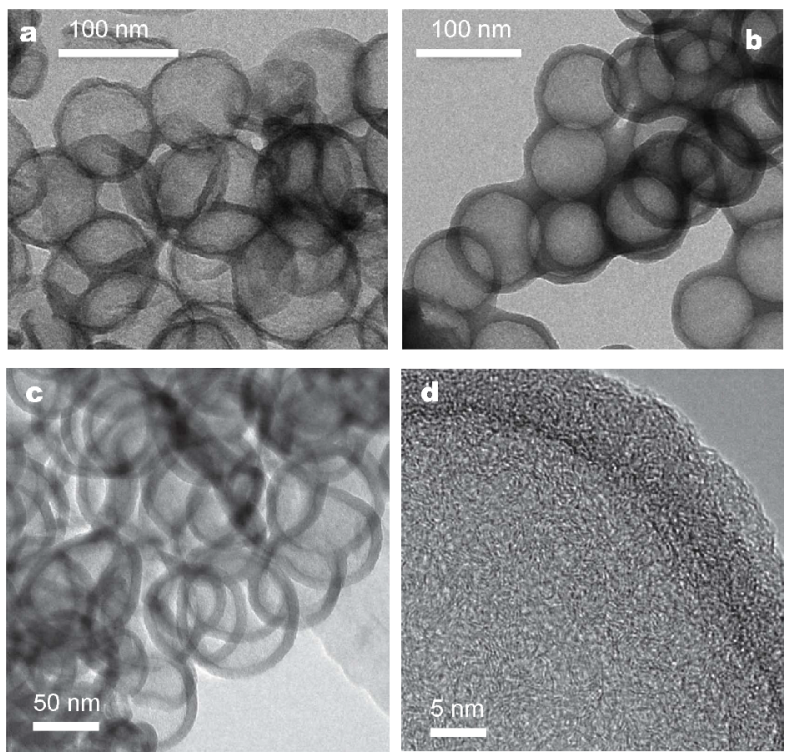

Figure 4 TEM micrographs of hydrothermal carbonization carbons derived from hydrolysis products after using silica nanoparticles as templates: (a) spruce, (b) corncobs. Reprinted with permission from Ref. [50] Copyright 2013, WILEY-VCH Verlag GmbH \& Co. KGaA. (c) TEM image and (d) HR-TEM image of hollow carbon nanospheres. Reprinted with permission from Ref. [51], Copyright 2012, WILEYVCH Verlag GmbH \& Co. KGaA.

connected carbon nanorings (TDICN) derived from waste batatas stalks and leaves (Fig. 5b). During the pyrolysis of batatas stalks and leaves, lignin, cellulose and hemicellulose are dehydrated and depolymerized to form a lot of oxygenated organic compounds, and subsequently cross-linking polymerization or thermal decomposition, accompanied by the release of water or gas, resulting in $3 \mathrm{D}$ interconnected structure. In short, the well-connected hollow carbon structure not only ensures an efficient and continuous electron transport, but also appears large electrode/electrolyte contact area to offer many active sites for charge-transfer reaction.

\section{Fibrous structure}

One-dimensional carbon materials, carbon fibers (CFs), have attracted a great deal of attention due to their excellent conductivity, high surface area, good flexibility, high tensile strength [23]. Moreover, in nature, the biomass material with fibrous structure can be found everywhere, such as flax [55], ramie [56,57], stem bark [58], lotus seedpods [59], bacterial cellulose [24, 60-64], because they usually contain lignin and cellulose. It is wellknown that electrospinning is a powerful and simple technique for fiber production [65]. Therefore, some researchers use lignin as raw material to obtain biomass-

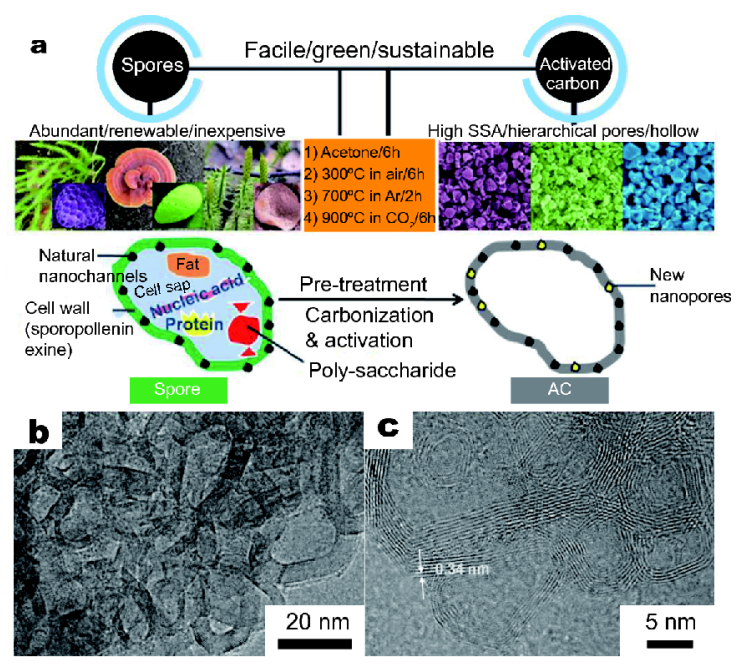

Figure 5 (a) Schematic illustration of the process to prepare hierarchically porous structured hollow microspheres of activated carbon from various spores (lycopodium clavatum, ganodorm alucidum and lycopodium annotinum). Reprinted with permission from Ref. [53] Copyright 2016, Royal Society of Chemistry. (b and c) TEM images of three dimensionally interconnected carbon nanorings. Reprinted with permission from Ref. [54], Copyright 2017, Royal Society of Chemistry.

based carbon fibers by electrospinning method [66,67]. After electrospinning, the lignin sub-microfibers were carbonized to generate carbon sub-microfibers with different connectivity and porosity. Berenguer et al. [67] found that the connectivity of fibers and the production of individual (loose) or interconnected CFs was controlled by a suitable heating rate. The slow heating rate stabilizes lignin rendering individual CFs, while a slightly fast heating rate resulted in the interconnected CFs at contact points (Fig. 6). The loose and interconnected CFs exhibited similar diameters in the range of $400 \mathrm{~nm}$ to $1.5 \mu \mathrm{m}$, whereas the porous structure of CFs favored the access and diffusion of ions.

To increase the porosity and surface area of carbon fibers, a porous structure is introduced into the carbon fibers. For example, Li et al. [68] reported N-doped porous carbon nanofibers by the pyrolysis of electrospun alginate nanofibers derived from seaweed. The egg-box shaped cobalt alginate nanofiber can create mesopores $(10-40 \mathrm{~nm})$ at the surface of $\mathrm{N}$-doped carbon nanofibers by removing the cobalt nanoparticles. The as-prepared $\mathrm{N}$ doped porous carbon nanofibers exhibited large surface area, multimodal pores, 3D interconnected network, proper N-doping and high graphitization structure (Fig. 7), which could not only provide low-resistance channels for electron transport but also increase the electroactive surface area [69]. 


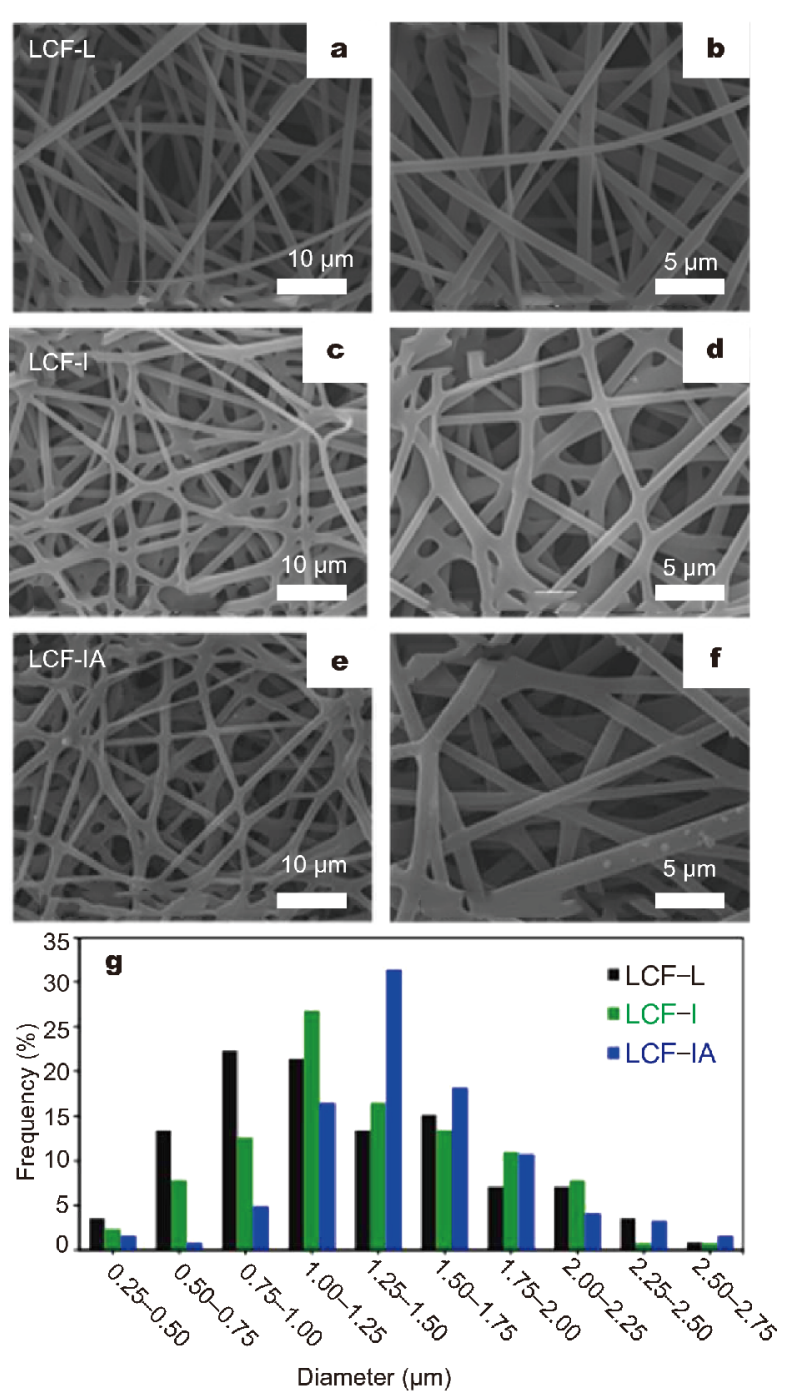

Figure 6 SEM images, covering different areas, of loose $(a, b)$, interconnected $(c, d)$ and interconnected + partially gasified (e, f) ligninbased carbon fibers (CFs). (g) Histogram of fiber diameters from SEM images. Reprinted with permission from Ref. [67], Copyright 2016, Royal Society of Chemistry.

Biomass-derived carbon fibers serve as a flexible conductive substrate to load pseudocapacitive active materials. For instance, $\mathrm{Hu}$ et al. [56] exploited for ramiederived carbon fibers (RCFs) as backbone to grow flakelike $\mathrm{MnO}_{2}$ (Fig. $8 \mathrm{a}-\mathrm{c}$ ). The fibrous carbon materials as the current collector can not only offer effective electron transport path but also increase the loading area. Recently, bacterial cellulose (BC), a 3D networks consisting of interconnected carbon nanofibers with a diameter of 20-100 nm (Fig. 8d, e), has been considered as a promising candidate for electrochemical electrode materials owning to abundant resource, low cost, good mechanical

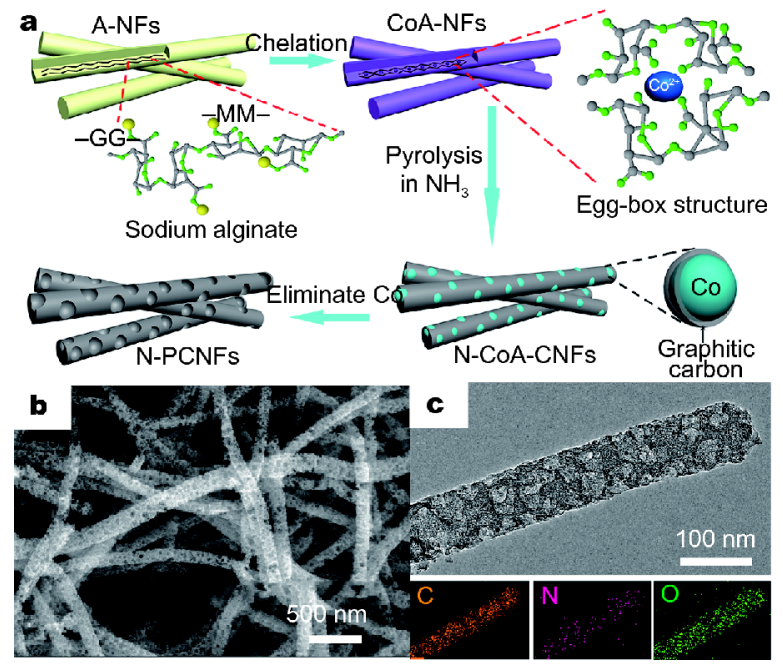

Figure 7 (a) Schematic illustration on the synthesis process of N-doped porous graphitic carbon nanofibers (N-PCNFs). (b) SEM image of NPCNFs-600. (c) Low-magnification TEM image and TEM-EDS mapping of N-PCNFs-600. Reprinted with permission from Ref. [68], Copyright 2015, American Chemical Society.

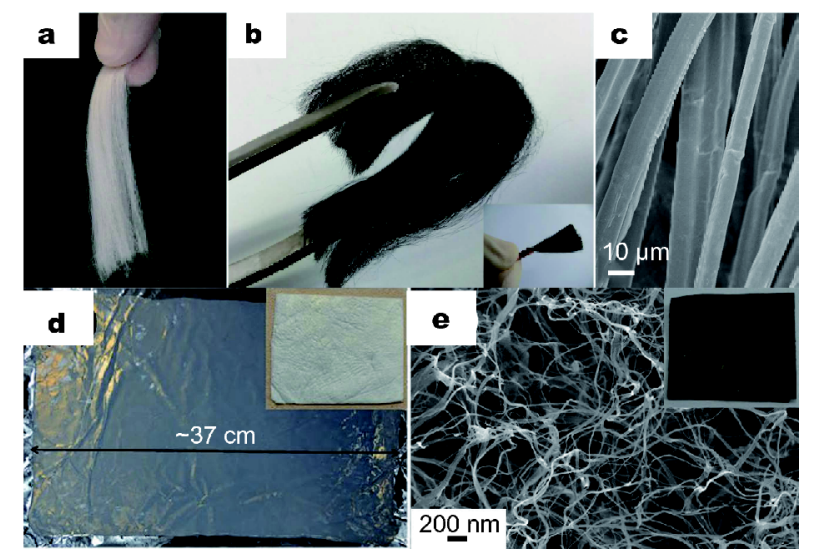

Figure 8 (a) Photograph of ramie fibers. (b) Photographs of the ramiederived carbon fibers (RCFs). (c) Low-resolution SEM image of the RCFs. Reprinted with permission from Ref. [56] Copyright 2016, American Chemical Society. (d) Photographs of the pristine bacterial cellulose pellicle and freezing dried bacterial cellulose membrane (inset) with size of $30 \times 40 \mathrm{~cm}^{2}$ and $4 \times 5 \mathrm{~cm}^{2}$, respectively. (e) FESEM image and photograph (inset) of $\mathrm{CBC}$ membrane. Reprinted with permission from Ref. [24], Copyright 2016, WILEY-VCH Verlag GmbH \& Co. KGaA.

strength and its fibrous unique structure $[62,63]$ which is an ideal template for growth of polyaniline [24,60,70], hydrotalcite [61], metal oxide [71] etc. Our group reported N-doped carbon networks derived from polyaniline-coated bacterial cellulose for supercapacitors. The asobtained carbon networks can act not only as supports, but also as conductive networks to integrate active elec- 


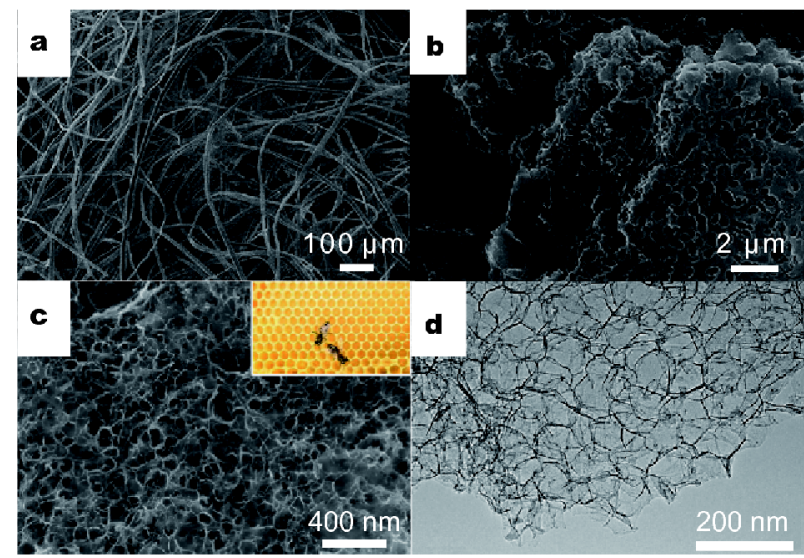

Figure 9 SEM images of (a) broussonetia papyrifera (BP) fiber and (b) BPC-700. Reprinted with permission from Ref. [58] Copyright 2015, Elsevier. (c) SEM and (d) TEM images of bacterial cellulose-based 3D honeycomb-like hierarchical structured carbon (HSC-0.5). Reprinted with permission from Ref. [61], Copyright 2016, Royal Society of Chemistry.

trode materials. As a result, the bacterial cellulose-derived carbon fibers serve as a lightweight current collector, flexible backbone and an effective electron transfer route.

Natural fibrous biomass materials can also be converted into another special structure. As reported by Wei et al. [58], broussonetia papyrifera (BP) stem bark with fibrous structure is used as a biomass precursor to prepare porous carbon (Fig. 9a). However, after hydrothermal reaction and pyrolysis activation, the BP fiber displays a continuous sponge-like branched framework and interconnected pores (Fig. 9b). Liu et al. [59] reported lotus seedpods (LS) as the biomass precursor. The fibers with a diameter of tens of nanometers became porous by pyrolysis and activation. Briefly, these plant biomass materials with multilevel layered structures (cellulose, hemicellulose and lignin) undergo the dissolution of the hot alkali, high temperature carbonization and activation, leading to complete separation of layers, meanwhile, many pores are left after the $\mathrm{KOH}$ etching at high temperature.

Chitin is one of the most abundant polysaccharides and exists in main form of chitin nanofibrils in marine creatures (such as shrimps and crabs). You et al. [72] used chitin fibers extracted from portunid to prepare polysaccharides nanosheets with the thickness of $\sim 27 \mathrm{~nm}$ by hydrophobization-induced interfacial assembly and further carbonizing into carbon nanosheets with a thickness as low as $\sim 3.8 \mathrm{~nm}$. Recently, our group prepared a 3D honeycomb-like hierarchical carbon by one-step carbonization/activation soaked in $\mathrm{KOH}$ solution of fibrous bacterial cellulose [61] (Fig. 9c, d). During this process, the structure transformation from nanofibers to nanosheets is due to the cross-linking of bacterial cellulose by $\mathrm{KOH}$. K-containing species acts as hard template to generate macropores as ion-buffering reservoirs, ensuring fast transport and diffusion of electrolyte ions into the electrodes during charge/discharge process. Importantly, $\mathrm{KOH}$ is used as a chemical activator to generate considerable micropores and mesopores to increase SSA, ensuring more effective electroactive sites for charge accommodation. Thus the fibrous biomass can be crosslinked, intertwined and integrated between the fibers to form an integral three-dimensional structure.

\section{Tubular structure}

Compared with fibrous carbon materials, tubular carbon materials can not only offer an effective electron transportation route, but also form a buffering space to rapid diffusion/migration for electrolyte ions from the bulk electrolyte solution to interior pores of electrode during charge/discharge process, significantly shortening the ion diffusion paths. Most of biomass materials possess intriguing hollow tubular structure, such as cotton [73-75], dandelion [76], poplar catkins [77], willow catkins [7882], which can be used as precursors to produce conductive carbon tubes. According to the literature, cotton fibers can still inherit hollow porous carbon tubes after carbonization and chemical activation (Fig. 10a) [73-75]. The tubular carbon materials with several millimeters in length offer ultra-long electronic and ionic pathway, while plenty of nanopores on the fiber walls created by $\mathrm{KOH} / \mathrm{NaOH}$ activation enable fast ion transport across the walls and enhance surface area for charge accommodation. As shown in Fig 10b, c, poplar [77] and willow [81] catkins display also hollow tubes after carbonization. In addition, the untreated dandelion is also tubular with a smooth surface [76]. Although the tubular structure of dandelion can be well reserved after high temperature carbonation treatment, the surface began to shrink, which may increase the contact area with ions in the electrolyte. Dong et al. [83] prepared N-doped foam-like carbon plates consisting of carbon tubes derived from pomelo peel by carbonization and subsequent $\mathrm{KOH}$ activation (Fig. 10d, e). The as-prepared carbon plates with macroporous network are composed of hollow tubes ranging from $20-50 \mu \mathrm{m}$, and these hollow tubes are interwoven and continuously coalesced. In a word, the tubular structure provides a path for transferring electrons and permeating ions while hollow structure forms buffering space during electrolyte ion de-intercalation to shorten the ion diffusion path. 


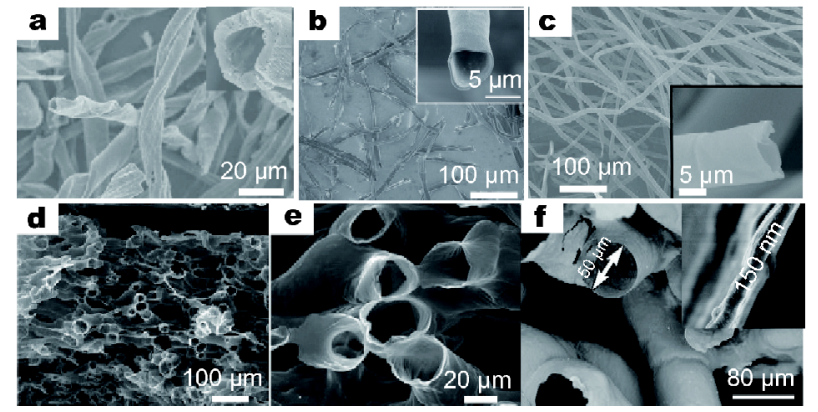

Figure 10 (a) SEM image of cotton-derived activated carbon fiber (aCF-6). Reprinted with permission from Ref. [74] Copyright 2016, American Chemical Society. (b) SEM images of poplar catkins-derived carbon microtubes. Reprinted with permission from Ref. [77] Copyright 2014, The Chemical Society of Japan. (c) The SEM images of willow catkin. Reprinted with permission from Ref. [81] Copyright 2016, Elsevier. (d, e) Typical cross-sectional view SEM images of pomelo-peelderived carbon tubes. Reprinted with permission from Ref. [83] Copyright 2016, WILEY-VCH Verlag GmbH \& Co. KGaA. (f) SEM images of higher magnification and the wall of the eggplant-derived macroporous carbon tubes. Reprinted with permission from Ref. [84], Copyright 2016, Royal Society of Chemistry.

On the other hand, the hollow tubes can also be used as ideal substrates for the growth and design of various inorganic materials. As an example, Qu et al. [84] reported a macroporous carbon tubes derived from eggplant by freeze-drying and carbonization, with a diameter of 40$50 \mu \mathrm{m}$, the thickness of the tube wall of $150 \mathrm{~nm}$ and smooth surface (Fig. 10f). These interconnected hollow tubes are favorable for the storage and fast diffusion of electrolyte ions, which can effectively enhance the rate capability for supercapacitors. Then, the thin walls are conducive to decrease mass ratio of the carbon when loading the same density of pseudocapacitive materials, thus improving the electrochemical performance of the nanocomposites.

\section{Sheet structure}

Two-dimensional (2D) carbon materials become one of the ideal candidates due to high aspect ratio, excellent conductivity, high SSA and good mechanical properties due to their atomic thickness. It is well known that graphene, a typical 2D material, has attracted a great attention as electrode materials owing to its high theoretical SSA and excellent electronic conductivity. However, large-scale, simple and environment-friendly production of graphene is subject to certain resistance. Additionally, during the electrode fabrication process their re-stacking or aggregation has also greatly hindered their further applications. Surprisingly, some researchers are successful for preparing graphene-like sheets by using biomass

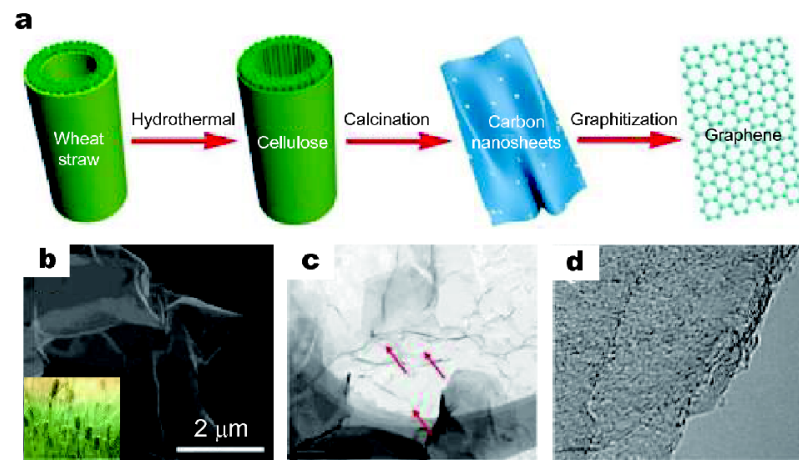

Figure 11 (a) Schematic diagram displaying the overall evolution of wheat straw into few-layer graphene. (b) SEM and (c and d) TEM images of few-layer graphene. Reprinted with permission from Ref. [86], Copyright 2016, Elsevier.

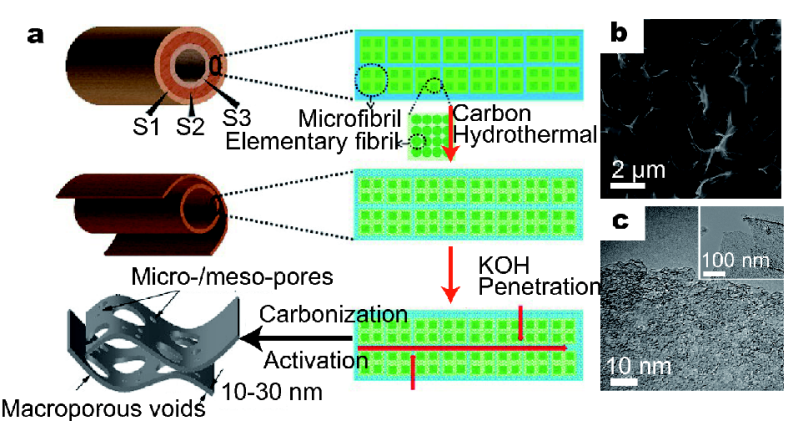

Figure 12 (a) Schematic of the synthesis process for the hemp-derived carbon nanosheets, with the three different structural layers S1-S3. (b) SEM micrograph highlighting the interconnected 2D structure of sample CNS-800. (c) High resolution TEM micrograph highlighting the porous and partially ordered structure of CNS-800. Reprinted with permission from Ref. [87], Copyright 2013, American Chemical Society.

(starch [85], wheat straw [26,86], hemp [87], coconut shell [88], inner shaddock skins [89]) as carbon source. As an example, Chen et al. [86] developed high-quality graphene sheets with ultrathin nanosheet frameworks (210 atomic layers) and graphite-like interlayer spacing $(0.3362 \mathrm{~nm})$ from wheat straw via combining hydrothermal and graphitization (Fig. 11). Moreover, Wang et al. [87] also reported a carbon nanosheet derived from hemp fibers by $\mathrm{KOH}$ activation (Fig. 12). In general, because wheat straw and hemp bast fibers have a multilayered structure composed of cellulose, semicellulose and lignin, most of semicellulose and part of lignin are converted into soluble organic compounds and the crystalline cellulose is partially carbonized by hydrothermal treatment. In the subsequent activation process, the $\mathrm{KOH}$ melt penetrates into the loose connection between the microfibers, resulting in separating layers as 
graphene-like sheets, reducing their thickness and generating micro and mesoporosity.

There are also researchers to prepare graphene-like carbon nanosheets by simultaneous activation-graphitization route using $\mathrm{FeCl}_{3}$ as graphitic catalyst and $\mathrm{ZnCl}_{2}$ as activating agent. $\mathrm{FeCl}_{3}$ can generate a carburized phase which acts as a template to limit the carbon graphitization in the $2 \mathrm{D}$ plane, while $\mathrm{ZnCl}_{2}$ can introduce a porous structure for increasing the SSA. As an example, Sun et al. [88] have reported carbon nanosheets synthesized by waste coconut shell by metal salts simultaneous activation-graphitization. Recently, Tian et al. [89] have also reported numerous interconnected carbon nanosheets with graphene-like structures fabricated from inner shaddock skins by simultaneous carbonization, $\mathrm{ZnCl}_{2}$ activation and $\mathrm{FeCl}_{3}$ catalysis. In the process of biomass turning into chars, a rapid contraction occurred in all the dimensions of the chars, leading to the generation of the thinner nanosheet structures. Notably, the iron catalyst can also form the $2 \mathrm{D} \mathrm{Fe}_{3} \mathrm{C}$ layers and be subsequently transformed to $a-F e$ layers as an in situ self-template. Importantly, the incompactly crumpled and folded carbon nanosheets assembled a mass of cage-like structures, which can act as ion-buffering reservoirs to enhance ion transport kinetics during the electrochemical process.

In addition, the biomass-derived carbon materials with 2D sheets have been prepared by carbonized leaf [34,9092], stalk [25,93], nutshell [94], waste coffee grounds [95], okara [96], eggplant [97], silk [98], fish scale [99], biomass-based molecules (chitosan [100] and gelatin [35]), etc. These biomass precursors themselves have a multiple layer structure or cause a new structural rearrangement to form 2D sheets during the pyrolysis. These interconnected sheets are porous, well-organized and crumpled together, which is conducive to the rapid diffusion of electrolyte ions. Ling et al. [100] reported porous carbon sheets from acidized chitosan by combining freeze-drying and high-temperature carbonization without adding any activation agents. The as-made carbon sheets exhibits interconnected pores (Fig. 13a), while the abundant micropores are formed inside the sheets due to the escape of produced gas during carbonization (Fig. 13b). Subsequently, the authors prepared carbon nanosheets with a thickness of 5-8 $\mathrm{nm}$ with ultrahigh aspect ratio of over $6,000-10,000$ by assembling gelatin molecules in longrange order on $2 \mathrm{D}$ boric acid hard template and subsequent annealing (Fig. 13c, d). The 2D carbon sheets not only provides low diffusive resistance to mass transport on a large electrode/electrolytes interface for chargetransfer process, but also offers a rapid ion transport

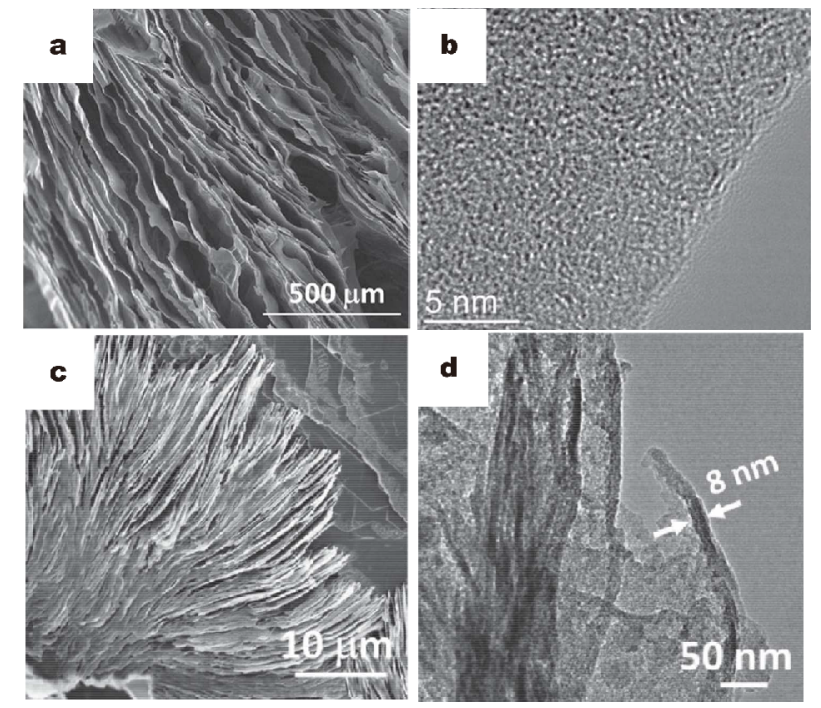

Figure 13 (a) SEM and (b) TEM images of carbon cryogel (G-CS-8). Reprinted with permission from Ref. [100]. Copyright 2015, IOP Publishing. (c) Cross-section SEM view of gelatin coated boric acid nanoplates. (d) cross-section TEM image of B/N-CSs. Reprinted with permission from Ref. [35], Copyright 2016, WILEY-VCH Verlag GmbH \& Co. KGaA.

pathway.

\section{Porous structures}

Porosity and reasonable pore size distribution of the electrode materials are very vital for the transport and diffusion of electrolyte ions. On the one hand, these special porous structures are derived from the structures of the biomass itself that are beneficial for absorbing nutritive ions and water from nature. These pores within biomass materials can be inherited during the preparation of carbon materials. On the other hand, biomass materials are usually composed of organic macromolecule substance, such as polysaccharides, proteins, nucleic acids, lipids. During high temperature pyrolysis or carbonation, a majority of macromolecules will be decomposed into $\mathrm{H}_{2} \mathrm{O}$ and $\mathrm{CO}_{2}$, and consequently escape from material to form pores. Biomass-derived carbon materials with special porous structures and coordinated pore size can also be obtained by adding some additional activator. Therefore, the porous structures of biomass-derived carbon materials can be carefully designed to shorten the distance of ion diffusion, facilitate the transmission of electrons and improve rate capability.

As we known, porous carbon materials can be classified according to their pore diameters as micropores (pore size $<2 \mathrm{~nm}$ ), mesopores $(2 \mathrm{~nm}<$ pore size $<50 \mathrm{~nm}$ ), and macropores (pore size $>50 \mathrm{~nm}$ ). It is worth noting that the appropriate pore size distribution of carbon materials 
plays an important role in improving the performances of the electrodes. Mesopores can act as reservoirs to shorten ion transport pathway or accelerate ion transport rate and micropores are favorable for achieving high SSA and increasing charge accommodation sites, especially for supercapacitors.

$\mathrm{Xu}$ et al. [94] reported 2D microporous carbons by pyrolysis and $\mathrm{KOH}$ activation of natural waste Pistachio nutshell. The as-prepared carbon has highly interconnected pores with the pore size of about $0.5-1 \mathrm{~nm}$, high micropore volume ratio of $83 \%$ and large surface area of about $1069 \mathrm{~m}^{2} \mathrm{~g}^{-1}$. Moreover, the biomass-derived carbon materials with abundant micropores can also be prepared from ginkgo leaves [101], cotton stalk [102], pine needles [103], acacia gum [104], pomelo peel [105] popcorn [106], cornstalk [107], walnut shell [108]. Furthermore, microporous surface area and pore volume depend on the amount of $\mathrm{KOH}$ and heat treatment temperature $[42,102,104]$. As the ratio of alkali/carbon varies from 1:1 to 6:1, the SSA and micropore volume of the carbon materials also increase [5,102]. With the increasing temperature, the SSA and pore volume of the carbon material also show a peak at a certain temperature [42] due to the collapse of the micropores at higher temperature $[97,103]$. In general, the biomass materials activated by $\mathrm{KOH}$ exhibit high specific surface up to 2500 $\mathrm{m}^{2} \mathrm{~g}^{-1}$, pore volume higher than $1.3 \mathrm{~cm}^{3} \mathrm{~g}^{-1}$ and narrow pore sizes between $0.5-2 \mathrm{~nm}$. Unfortunately, the dominant microspores and severe pore tortuosity in the micrometer-sized carbon granules limit ion transport, increase ion diffusion pathway and thus reduce the electrochemical performance, especially at high current density.

Mesopores can store more electrolyte ions than micropores and results in short ion transport pathway and good rate capability, beneficial to enhance their electrochemical performance. In order to obtain mesoporous biomass-derived carbon materials, it is necessary to choose the suitable methods, such as physical activation with stream or carbon dioxide, $\mathrm{ZnCl}_{2}$ or $\mathrm{H}_{3} \mathrm{PO}_{4}$ activation, and mesoporous templates. $\mathrm{ZnCl}_{2}$ is considered more effective and inexpensive activating agents for producing mesoporous biomass-derived carbon materials. Recently, our group prepared N-doped porous carbons with high SSA $\left(1607 \mathrm{~m}^{2} \mathrm{~g}^{-1}\right)$ and high mesopore ratio (91\%) by $\mathrm{ZnCl}_{2}$ activation of auricularia [109] (Fig. 14). Moreover, coconut shell [110], sugar cane bagasse and sunflower seed hull [111] have been reported as carbon precursors to prepare carbon materials with mesoporous structure by $\mathrm{ZnCl}_{2}$ activation.

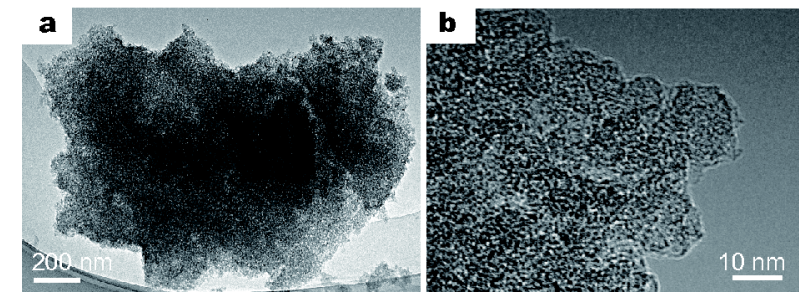

Figure $14(\mathrm{a}, \mathrm{b})$ TEM images of $\mathrm{N}$-doped mesoporous carbon building (N-MCB). Reprinted with permission from Ref. [109], Copyright 2016, Royal Society of Chemistry.

Niu et al. [112] prepared mesoporous carbons through direct carbonization of cattle bones without any additional activators and templates. The as-prepared mesoporous carbons possess the high SSA $\left(2096 \mathrm{~m}^{2} \mathrm{~g}^{-1}\right)$, largest mesopore volume $\left(1.829 \mathrm{~cm}^{3} \mathrm{~g}^{-1}\right)$ and a narrow mesopore size distribution centered at approximately 4.0 $\mathrm{nm}$, which are attributed to self-activation induced by hydroxyapatites within the cattle bones. However, large mesopores will decrease the SSA of porous carbon and the double-layer capacitance. Therefore, a rational design of carbon materials with well balance between mesoporosity and microporosity is vital to achieve high performances of the electrode materials.

The porous carbon-based materials with interconnected micro-/meso-/macropores improve energy storage performance. These hierarchical pores function as either active sites for ion adsorption, ion transport, or ion reservoirs. The hierarchical porous carbon has high energy storage capacity and excellent rate capability. So far, various biomass, such as bagasse [113,114], endothelium corneum gigeriae galli [115], silk [98], auricularia [116118], spores [53], lignin [119], cellulose [120], cotton [73], honeysuckle [121], lotus seedpods [59], enteromorpha $[122,123]$, willow catkins [78], sheep manure [124], tobacco rods [125], corn leaf [126], bacterial cellulose [62], have been widely used as precursors to prepare hierarchical porous carbons through carbonization and activation process. Hou et al. [98] have prepared hierarchical porous $\mathrm{N}$-doped carbon nanosheets (HPNC-NSs) from natural silk by the metal salt activation-graphitization (Fig. 15a, b). The as-obtained hierarchical porous carbon possesses remarkable SSA $\left(2494 \mathrm{~m}^{2} \mathrm{~g}^{-1}\right)$, high total pore volume $\left(2.23 \mathrm{~cm}^{3} \mathrm{~g}^{-1}\right)$, a continuous pore distribution within the range of $2-100 \mathrm{~nm}$ and the average pore size diameter $4.6 \mathrm{~nm}$ (Fig. 15c, d). These hierarchical pores facilitate rapid charge transfer, high charge capacity, adequate mass transport, easy electrolyte access and minimized polarization effects.

Taking advantage of the self-absorption of biomass 

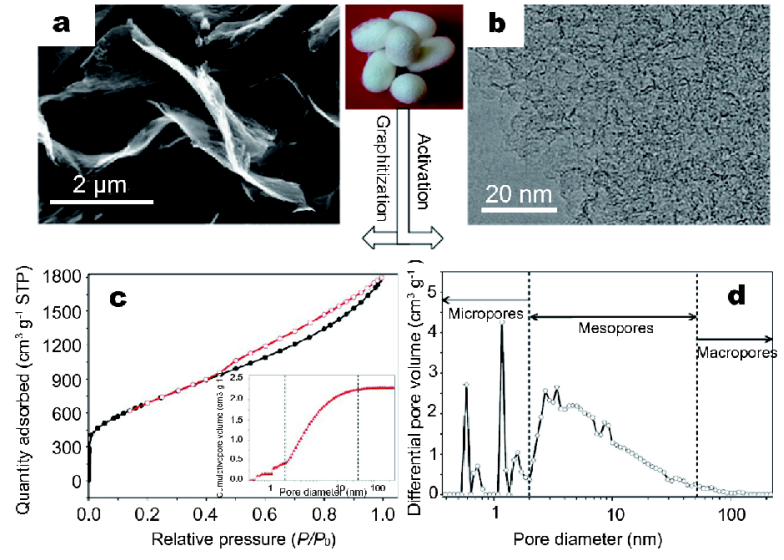

Figure 15 (a) SEM and (b) TEM images of hierarchical porous nitrogen-doped carbon nanosheets (HPNC-NS). (c) Nitrogen adsorptiondesorption isotherm (inset: cumulative pore volume) and (d) pore size distribution of an HPNC-NS. Reprinted with permission from Ref. [98], Copyright 2015, American Chemical Society.

materials, such as the roots, stems and leaves of plants, and agaric, can effectively absorb activator. For example, Cai et al. [127] prepared interconnected hierarchical porous carbon framework by the pyrolysis of $\mathrm{KOH}$-adsorbed moringa oleifera branches (MOBs). This method can avoid using excessive activation agents and violent reactions that easily irreversibly destroy the novel structure of the precursor. The as-prepared hierarchical por- ous carbon still inherits the unique structure of MOBs (Fig. 16a-h), with plenty of micropores, appreciable amount of mesopores and some macropores (Fig. 16i), which can effectively shorten ion diffusion paths and enhance the structural stability during rapid charge/discharge process. Generally, hierarchically interconnected micro-/meso-/macro-pores can provide unimpeded channels for electrolyte ions, result in fast ion diffusion and transport during rapid charge/discharge process and ensure high rate capability and remarkable power density.

\section{SURFACE CHEMISTRY}

Introducing heteroatom has been considered as a promising approach to enhance the capacity, electronic conductivity and surface wettability and promotes the electrode/electrolyte interactions and charge transfer $[9,128]$. More importantly, a certain amount of $\mathrm{N}, \mathrm{O}$ derived from carbohydrate, protein and other organic macromolecules, in the biomass material can form selfdoping carbon materials. A variety of heteroatom-doped or co-doped biomass-derived carbons from the biomass itself or the additional dopant, such as $\mathrm{NH}_{4} \mathrm{Cl}$, urea, melamine, $\mathrm{NH}_{3}$, thiourea, $\left(\mathrm{NH}_{4}\right)_{2} \mathrm{SO}_{4},\left(\mathrm{NH}_{4}\right)_{2} \mathrm{HPO}_{4}$, $\mathrm{H}_{3} \mathrm{PO}_{4}, \mathrm{H}_{3} \mathrm{BO}_{3}$, have been explored as electrode materials. To date, nitrogen is the most widely studied heteroatom for biomass-derived carbon materials, which can promote the reaction activity and electronic conductivity. A por-

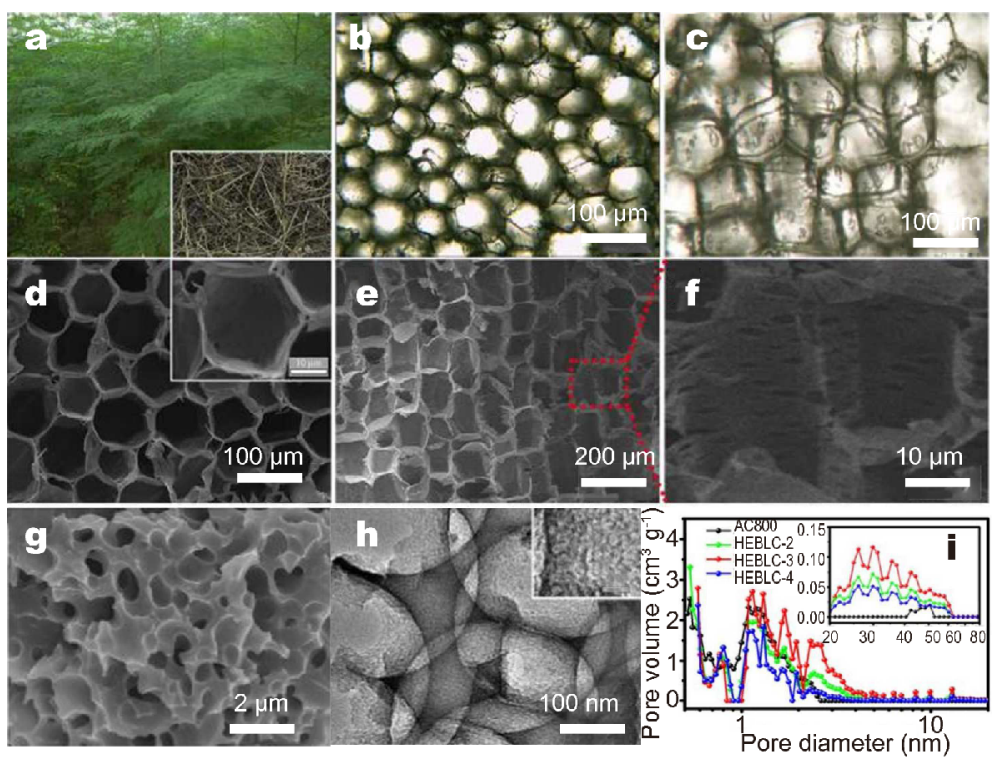

Figure 16 (a) Digital photograph of moringa oleifera trees. Inset in (a) shows a photograph of moringa oleifera branches (MOBs). Optical photographs of MOBs in cross section (b) and longitudinal section (c). FESEM images of MOBs in cross section (d) and longitudinal section (e). (f) Magnified FESEM image of the red square in (e). (g) SEM and (h) TEM images of the hierarchical egg-box-like carbons (HEBLCs). (i) The pore size distribution curves of HEBLCs. The inset in (i) shows the pore size distribution curves from 20 to $80 \mathrm{~nm}$. Reprinted with permission from Ref. [127], Copyright 2016, American Chemical Society. 
tion of biomass material itself has abundant nitrogen element, such as soyabean $[129,130]$, okara [96], tofu [131], crab and shrimp shells [49,132,133], oatmeal [22], endothelium corneum gigeriae galli [115], silk [98], chitosan [100], potato waste residue [134], palm-leaf [135], grlatin [35], algae [122]. The nitrogen content in these biomass-derived carbon is generally more than $4 \%$. For example, Yang et al. [96] reported a N-doped carbon sheets derived from okara with a high nitrogen content of 9.89 at $\%$. Other biomass derived carbons, such as wheat flour [136], stem bark [58], MOB [127], tobacco rods [125], perilla frutescens [34], pine needle [103], had 1 at $\%$ nitrogen. In order to increase the nitrogen content of biomass-derived carbon materials, some nitrogen-containing dopants $\left(\mathrm{NH}_{4} \mathrm{Cl}\right.$ [109], $\left(\mathrm{NH}_{4}\right)_{2} \mathrm{SO}_{4}$ [137], $\mathrm{NH}_{3}$ [138], urea [114], melamine [139]) were introduced. Because of the strong electronegativity of nitrogen and the hybridization of nitrogen lone pair electrons with the $\pi$ electrons in carbon, $\mathrm{N}$-doped biomass-derived carbon material is beneficial to bind the effective charge for energy storage. In addition, the existence of nitrogen atoms also creates defects in carbon and generates more active sites for energy storage [137].

Oxygen doped into biomass-derived carbon materials is also favorable for introducing faradic pseudocapacitive and enhancing the wettability in aqueous electrolyte $[140,141]$. Feng et al. [142] prepared oxygen-rich activated carbon from dragon fruit skin, momordica grosvenori skin and firmiana catkins. The oxygen content of the obtained activated carbon can reach 23.32 at $\%$. However, it has been reported that oxygen-rich carbon exhibited lower capacitance than nitrogen-rich carbon, because surface carboxyl groups hindered electrolyte diffusion into the pores in carbon $[5,143]$.

Similar to the $\mathrm{N}$ and $\mathrm{O}$ doping, the P, F, S, B-doping can also improve the electrochemical properties of biomass-derived carbon materials. Yi et al. [144] prepared a $\mathrm{P}$-doped biomass-derived carbon through the pyrolysis of lignocellulose immersed in $\mathrm{ZnCl}_{2} / \mathrm{NaH}_{2} \mathrm{PO}_{4}$ aqueous solution. Phosphorus with high electron-donating ability is anticipated to remarkably enhance the charge storage and transport capability. Wang et al. [145] reported F-doped carbon with the content of about 1.1 at\% fluorine through the pyrolysis of lotus petioles. The F-doping is prone to increase the repulsive interaction between carbon layers, thus enlarging the carbon interlayer distance, which is conducive to the insertion and de-insertion of large-sized electrolyte ions, especially for sodium ions. Analogously, $S$ doping in carbon can also enlarge carbon interlayer distance, meanwhile act as an additional active site for sodium storage $[9,92,146]$.

In addition to a single heteroatom-doping, some researchers have investigated the influence of two or more different heteroatom co-doping for electrochemical properties of biomass-derived carbon materials. Because $\mathrm{N}$ doping can enhance the electronic conductivity and wettability, while $\mathrm{O}, \mathrm{B}, \mathrm{S}$ or $\mathrm{P}$-doping can provide the pseudo-capacitance, enlarge the carbon interlayer distance and increase additional active sites, $\mathrm{N}, \mathrm{O}$ co-doping $[34,122,123,129,138], \mathrm{N}, \mathrm{B}$ co-doping [35,147], N, S codoping $[81,92,146,148]$ and $\mathrm{N}, \mathrm{P}$ co-doping $[39,99,149]$ have been designed to further improve the electrochemical performances of biomass-derived carbon materials. For instance, Sun et al. [147] reported a separated $\mathrm{N}, \mathrm{B}$ co-doped porous graphitic carbon from nitrogencontaining chitosan through coordinating boric acid and $\mathrm{Fe}$ catalyst, and followed by $\mathrm{ZnCl}_{2}$-activation process. The electron-rich $\mathrm{N}$ and electron-deficient $\mathrm{B}$ can create a unique electronic structure with the synergistic effect of two heteroatoms, resulting in high electrochemical performances in dual doped carbon materials. $\mathrm{Xu}$ et al. synthesized N, S co-doped porous carbon by carbonizing the shell of broad beans and consequent chemical activation [148]. The resulting carbon material exhibited that the amounts of $\mathrm{N}$ and $\mathrm{S}$ were 2.0 at $\%$ and 0.94 at $\%$, respectively, which can not only enhance the specific capacitance for supercapacitors but also improve the specific capacity and rate capability in lithium-ion and sodium-ion batteries. Furthermore, Qu et al. [132] synthesized a ternary $\mathrm{N}, \mathrm{O}$ and $\mathrm{P}$ co-doped porous carbon by $\mathrm{H}_{3} \mathrm{PO}_{4}$ activation of shrimp shell. Importantly, shrimp shell itself possess $5.32 \mathrm{wt} \%$ nitrogen and $40.2 \mathrm{wt} \%$ oxygen, and phosphorus atom can also be in situ introduced into the carbon framework by $\mathrm{H}_{3} \mathrm{PO}_{4}$ activation. Thus, $\mathrm{N}$ and $\mathrm{O}$ doping can enhance the pseudo-capacitance, electronic conductivity and wettability, and $\mathrm{P}$ doping can widen the operation voltage window, resulting to improve the energy density of carbon electrode materials. In general, the introduction of heteroatoms in biomass-derived carbon materials result in the enlarged interlayer distance, increased SSA, distorted structure, enhanced the capacitance by providing the pseudo-capacitance, improved wettability as well as conductivity of carbon electrode materials.

\section{SYNTHESIS METHODS OF BIOMASS- DERIVED CARBON MATERIALS}

\section{Activation}

Pyrolysis is considered to be the most straightforward 
way of synthesizing biomass-derived carbon materials. However, the produced carbon materials usually suffer from low SSA and poor porous structures, essential for electrochemical applications. Activation strategies, including physical and chemical activation, could be employed to further adjust the porous structures and increase the SSA. Physical activation technique involves carbonization of a biomass material then activating the resulting char with suitable oxidizing gases by air, carbon dioxide $\left(\mathrm{CO}_{2}\right)$, steam or their mixtures at $600-1200^{\circ} \mathrm{C}$. Among those oxidizing gases, $\mathrm{CO}_{2}$ is very promising due to its clean, easy to handle [150]. For example, Guo et al. [53] used $\mathrm{CO}_{2}$-activation method to prepare porous carbon, where the spore precursors were first pre-processed to remove the lipids and sporoplasm, and then the products obtained were carbonized in argon gas flow at $700^{\circ} \mathrm{C}$ for $2 \mathrm{~h}$. Subsequently, activation was carried out in $\mathrm{CO}_{2}$ flow at $900^{\circ} \mathrm{C}$ for $6 \mathrm{~h}$. The achieved activated carbon exhibited a high surface area of $3053 \mathrm{~m}^{2} \mathrm{~g}^{-1}$ and a porous volume of $1.43 \mathrm{~cm}^{3} \mathrm{~g}^{-1}$. Although the physical activation represents an environment-friendly way of producing biomass-derived carbons, it has to face the challenges of high conversion temperature, long activation time and low porosity.

Chemical activation does not require high conversion temperature and long activation time. Simultaneously, the produced carbon materials exhibit wide pore size distribution and high SSA. In this progress, the biomass precursor is mixed with some activating agents such as $\mathrm{KOH}, \mathrm{NaOH}, \mathrm{KHCO}_{3}, \mathrm{ZnCl}_{2}, \mathrm{H}_{3} \mathrm{PO}_{4}, \mathrm{H}_{2} \mathrm{SO}_{4}$, then simultaneously carbonization and activation are carried out at $300-950^{\circ} \mathrm{C}$. Among the activating agents, $\mathrm{KOH}$ has been explored for the activation of biomass-derived carbons in elm samara [91], honeysuckle [121], lignin [151], cabbage leaves [152], willow catkins [80] and so on $[108,153]$. For example, our group prepared a series of biomass-derived carbons by one-step activating cattail [154], willow catkin [81], bacterial cellulose [61], soybeans [130], and wheat flour [136] with $\mathrm{KOH}$ activation. In a typical example, wheat flour and $\mathrm{KOH}$ were firstly mixed with a mass ratio of $1: 1$ and subsequent activation at 700 for $2 \mathrm{~h}$. Compared with the sample without $\mathrm{KOH}$ activation $\left(5 \mathrm{~m}^{2} \mathrm{~g}^{-1}\right)$, the BET surface area was significantly increased to $1313 \mathrm{~m}^{2} \mathrm{~g}^{-1}$. Furthermore, in chemical activation, a two-step process including thermal carbonization and subsequently activation processes are also usually required $[102,103,105]$. Ma et al. [102] prepared cotton stalk-derived activated carbon with high surface area $1964.46 \mathrm{~m}^{2} \mathrm{~g}^{-1}$ and pore volume of $1.03 \mathrm{~m}^{3} \mathrm{~g}^{-1}$ through a two-step carbonization and che- mical activation process. Zhu et al. [103] obtained microporous carbon frameworks with ultrahigh SSA (up to $2433 \mathrm{~m}^{2} \mathrm{~g}^{-1}$ ) through the carbonization of pine needles and followed by $\mathrm{KOH}$ activation.

Although chemical activation represents an effective way of producing biomass-derived activated carbon with a variety of porous structures and high SSA, its wider application is still limited due to large amounts of harmful activating agent and cleaning agent and low yield. For cost-effective and eco-friendly developments, simple processes leading to biomass-derived carbon materials with a high surface area are still needed. In situ self-activation, which is a one-step carbonization of biomass with inherent inorganic salts or pyrolysis of biomass without additional activation reagents, would be a promising route to produce high surface area carbon. Selfactivation biomass-derived carbon materials have been successfully prepared by carbonization of cattle bone powder [112], eggplant [97], cellulose [155], dead leaves [156], etc. Yang et al. [157] prepared celery stem-derived activated carbon with high SSA of $2194 \mathrm{~m}^{2} \mathrm{~g}^{-1}$ through a one-step carbonization without any extra activation process.

\section{Hydrothermal carbonization}

There is also a powerful method, denoted as hydrothermal carbonization (HTC) technique, which was firstly reported by Bergius for transforming cellulose to coal-like materials in 1913 [158], and further developed by Berl and Schmidt [159]. Recently, the HTC of biomass precursors, including eucalyptus sawdust [160], fungi $[117,161]$, papyrifera bark [162], pine cones [163], tobacco rods [125], and bagasse [113], has been extensively explored for the preparation of carbon materials at $180-$ $250^{\circ} \mathrm{C}$, owing to its simplicity, cost-effective and nonpollution [164]. The chemical reaction involved in the HTC process comprises five steps: hydrolysis, dehydration, decarboxylation, polymerization, and aromatization [30]. It results in HTC carbon materials with SSA ranging from 1.3 to $250 \mathrm{~m}^{2} \mathrm{~g}^{-1}$ depending on the different carbon precursors, such as peanut hull [165], palm empty fruit bunches [166], pinewood [167], sunflower stem [168], olive stone [168], walnut shell [168], hazel nutshell [169], barley straw [170], auriculariaes [117,161] and ovalbumin [171]. Although HTC represents a low-cost process of producing carbonaceous directly from biomass materials, carbons obtained by HTC usually exhibit less pores and low SSA. Hence, much effort has been made to improve the porosity and SSA of HTC-derived carbons, such as adding templates [172] or additives [173]. Hydrothermal 
carbonization of biomass improves the chemical characteristics of hydrochar products which make them efficient as a precursor for activation [174]. Yang et al. [175] used hydrochar from hemp as precursor to prepare highsurface area carbons (up to $2879 \mathrm{~m}^{2} \mathrm{~g}^{-1}$ ). In addition to improve the porosity and SSA, the chemistry property of the HTC materials can also be moderated hydrothermally by adding amino acid, glycoprotein and so on [176].

\section{BIOMASS-DERIVED CARBON MATERIALS FOR ENERGY STORAGE APPLICATIONS}

\section{Biomass-derived carbon materials for supercapacitors}

Supercapacitors (SCs) are a kind of energy storage devices that provide higher power density, cycle efficiency, and charge/discharge rates than secondary battery. However, supercapacitors suffer from low energy density (4-10 W h $\mathrm{kg}^{-1}$ ), which would limit their practical applications [4]. The design of novel electrode materials with high power and energy densities is necessary. Exactly, biomass-derived carbon materials are fully equipped with these characteristics as electrode materials for supercapacitor. Usually, the biomass-derived carbon materials possess interconnected porous networks, which can provide multidimensional electron transport pathways and shorten transport distances between electrode and electrolyte [31]. Importantly, the biomass-derived carbon materials are resourceful, renewable, low cost and environmentally friendly. All the characteristics strongly suggest that biomass-derived carbon could be qualified for the electrode of supercapacitors. To date, various biomass-derived carbon materials with high SSA, abundant pore structure and modified functional groups have been prepared, such as the stems $[87,102,157,177-179]$, leaves $[34,90,101,103,126]$, seeds $[48,77,79,154]$, fructus [180-182], pericarp [88,89] of plants, nut shells [94,143,183-185], fungi $[53,109,186-188]$, abandoned food $[96,131,189]$, shellfish $[49,72,133]$, animal tissue $[112,115,124]$, polysaccharide $[44,85,147,155,190]$, protein [137].

Energy density $\left(1 / 2 C V^{2}\right)$ of the supercapacitor can be increased by enhancing the specific capacitance of the electrode material and widening the potential window of the supercapacitors. As for biomass-derived carbon materials, the high SSA and abundant porous structure are beneficial to increase the electro-sorption sites of ions to improve specific capacitance. However, excessive pores lead to the collapse of the interconnected porous structure and cause more point-to-point contact to reduce the conductivity of the carbon material.
Appropriate pore structure can introduce additional oxidation-reduction reaction by the modification of surface functional group or heteroatom to increase the specific capacity. For example, Ling et al. [35] prepared B/N co-doped carbon nanosheets by assembling the gelatin molecule in long-range order on 2D crystals of boric acid and followed by annealing. The $\mathrm{B}$ and $\mathrm{N}$ contents of the carbon materials were $3.3 \mathrm{wt} \%$ and $8.6 \mathrm{wt} \%$, respectively. The $\mathrm{B} / \mathrm{N}$ co-doped carbon delivered high specific capacitance of $358 \mathrm{~F} \mathrm{~g}^{-1}$ at $0.1 \mathrm{~A} \mathrm{~g}^{-1}$, outstanding rate capability and long lifetime, attributed to heteroatom doping and unique microstructure. Moreover, biomass-derived carbon materials as a carrier to grow or load the pseudocapacitance material (metal oxide or conductive polymer) can improve the specific capacitance of the carbon electrode material [84]. These carbon-based composites are used as electrodes to assemble into an asymmetric supercapacitor, which can increase its voltage window to obtain high energy density supercapacitors $[24,61,191,192]$. Chen et al. [192] designed an all-woodstructured asymmetric supercapacitor (ASC) by utilizing activated wood carbon (AWC) as anode, with a thin wood membrane as separator and electrodeposition obtained $\mathrm{MnO}_{2} /$ wood carbon $\left(\mathrm{MnO}_{2} @ \mathrm{WC}\right)$ as cathode (Fig. 17a). The wood-derived carbon material possesses multi channels, low tortuosity, high ionic/electronic conductivities and high structure stability (Fig. 17b-e). The ASC device exhibits a high areal capacitance $\left(3.6 \mathrm{~F} \mathrm{~cm}^{-2}\right)$, high energy/power densities $\left(\sim 1.6 \mathrm{~mW} \mathrm{~h} \mathrm{~cm}^{-2}\right.$ at 1044 $\mathrm{mW} \mathrm{cm}^{-2}$ ) and long cycling life even using highly loaded electrodes $\left(\sim 75 \mathrm{mg} \mathrm{cm}^{-2}\right)$ (Fig. 17f-k). Moreover, this supercapacitor is highly environmentally friendly and biodegradable due to the all-wood-derived components.

It has been reported that P-doped biomass-derived carbon can also widen the electrochemical window of supercapacitors [132,180]. For example, Huang et al. [180] prepared phosphorus-rich carbons (PCs) through phosphoric acid activation of waste coffee grounds. The results suggested that the $\mathrm{P}$-doped carbon can be operated very stably in $1 \mathrm{~mol} \mathrm{~L}^{-1} \mathrm{H}_{2} \mathrm{SO}_{4}$ at $1.5 \mathrm{~V}$ with only $18 \%$ degradation after 10,000 cycles at a current density of $5 \mathrm{~A} \mathrm{~g}^{-1}$. Due to the wide electrochemical window, a supercapacitor assembled with $\mathrm{P}$-doped carbon electrode had a high energy density of $15 \mathrm{~W} \mathrm{~h} \mathrm{~kg}^{-1}$ at a power density of $75 \mathrm{~W} \mathrm{~kg}^{-1}$.

Although biomass-derived carbon materials with large SSA and abundant pore structure exhibit high gravimetric performances, they suffered from poor volumetric performances due to a low bulk density or high porosity [193]. Recently, our group prepared densely porous layer- 
a
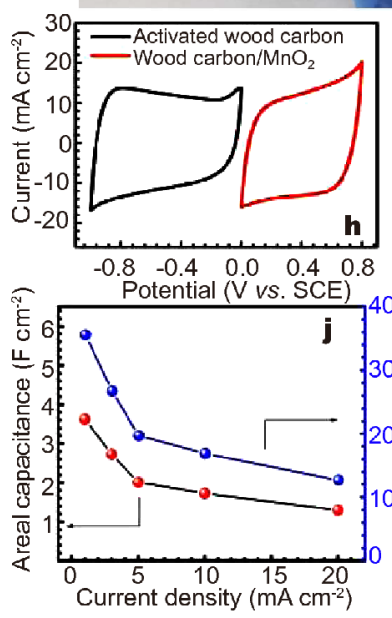
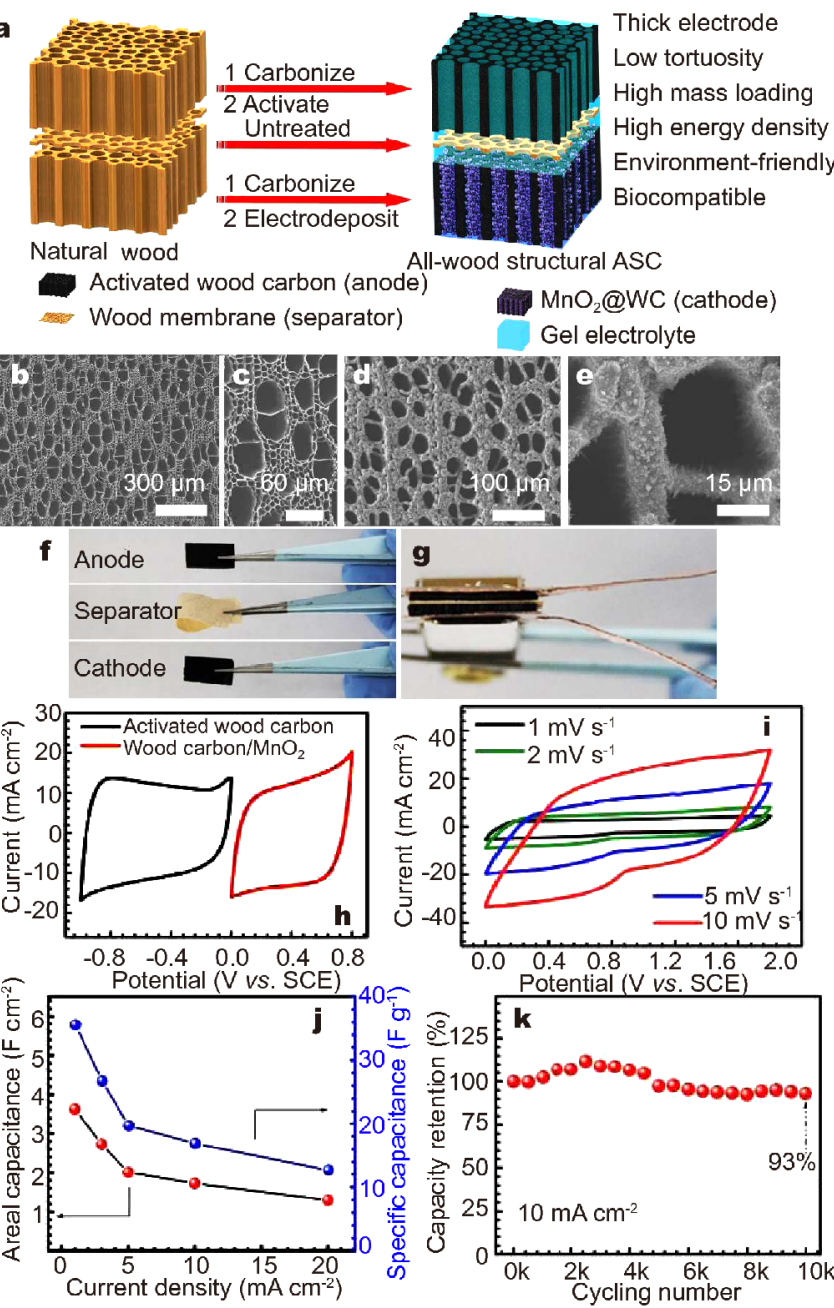

Thick electrode Low tortuosity High mass loading High energy density Environment-friendly Biocompatible

All-wood structural ASC $\mathrm{MnO}_{2} @ W C$ (cathode) Gel electrolyte

Figure 17 (a) Graphical illustration of the design concept and construction process of the all-wood-structured supercapacitor. (b, c) SEM images for the activated wood carbon (AWC). (d, e) SEM images for the wood carbon $/ \mathrm{MnO}_{2}\left(\mathrm{MnO}_{2} @ W C\right)$ composite. (f) Pictures of the AWC anode, wood separator and $\mathrm{MnO}_{2} @ W C$ cathode. (g) Picture of the allwood structured all-solid state asymmetric supercapacitor. Electrochemical performance of the AWClwood separator\|MnO $\mathrm{MnW}_{2} @ \mathrm{ASC}$ : (h) Typical CV curves of the AWC anode and $\mathrm{MnO}_{2} @ W C$ cathode between the potential range of -1 to $0.8 \mathrm{~V}$, (i) $\mathrm{CV}$ curves at various scan rates, $(j)$ rate performances, $(k)$ cycling performance. The specific capacitances are calculated based on the total mass of both electrodes. Reprinted with permission from Ref. [192] Copyright 2017, Royal Society of Chemistry.

stacking carbon (PGC) through hydrothermal treatment of fungus (Auricularia) and subsequent carbonization [117]. Layer-stacking carbon derived from cell walls of fungus with high surface area $\left(1103 \mathrm{~m}^{2} \mathrm{~g}^{-1}\right)$, high bulk density (about $0.96 \mathrm{~g} \mathrm{~cm}^{-3}$ ) and hierarchically interconnected porous framework (Fig. 18a-e) provide more storage sites, shorten transport paths for electrolyte ions and enhance the overall conductivity of the electrode. The resulting carbon electrode shows ultra-high volumetric capacitance of $360 \mathrm{~F} \mathrm{~cm}^{-3}$ and excellent cycling stability with $99 \%$ capacitance retention after 10,000 cycles (Fig. 18f, g). More importantly, the as-assembled symmetric supercapacitor delivers superior volumetric energy density of $21 \mathrm{~W} \mathrm{~h} \mathrm{~L}^{-1}$. Subsequently, our group successfully synthesized a functionalized porous carbon through heattreatment of $\mathrm{KOH}$-soaked soybeans [130]. The as-obtained carbon material showed $\mathrm{O}, \mathrm{N}$-doped interconnected porous carbon framework, high surface area $\left(580 \mathrm{~m}^{2} \mathrm{~g}^{-1}\right.$ ) and high packing density (up to $1.1 \mathrm{~g} \mathrm{~cm}^{-3}$ ) (Fig. 18h, i). As an electrode material for supercapacitors, it exhibits an ultra-high volumetric capacitance of $468 \mathrm{~F}$ $\mathrm{cm}^{-3}$, about 6 times higher than Maxsorb commercial activated carbon, as well as excellent cycling stability (Fig. 18j). And the as-fabricated symmetric supercapacitor delivers high volumetric energy density of $28.6 \mathrm{~W} \mathrm{~h} \mathrm{~L}^{-1}$. In general, in order to adapt to the development of energy storage in contemporary miniaturized electronic devices, a balance between carbon density and porosity is needed to be considered to accommodate high gravimetric and volumetric properties. As supercapacitor electrode, it is important to appropriately increase the SSA, optimize the design of the pore structure, heteroatom doping, and load the pseudostructure material for the biomass-derived carbon materials.

\section{Biomass-derived carbon materials for lithium-ion batteries}

Lithium-ion batteries, as one of the most promising energy storage devices, have attracted a great deal of attention from electric vehicles and hybrid electric vehicles, attributed to their high energy density, low self-discharge and long cycle life. Usually, lithium-ion batteries often employ transition metal oxides (such as $\mathrm{LiCoO}_{2}, \mathrm{LiFePO}_{4}$, $\left.\mathrm{Li}_{3} \mathrm{~V}_{2}\left(\mathrm{PO}_{4}\right)_{3}, \mathrm{LiMn}_{2} \mathrm{O}_{4}\right)$ as cathode and graphitic carbon as anode. It is well known that graphite is the most commonly used as anode material for commercial lithium-ion batteries because of its low cost and low electrochemical potential with respect to lithium metal. However, one $\mathrm{Li}$ ion can be intercalated per $6 \mathrm{C}$ atoms, resulting in graphitic carbon with a limited capacity of $372 \mathrm{~mA} \mathrm{~h} \mathrm{~g}^{-1}$. Unfortunately, the graphite anode suffers from poor rate capability due to a safety hazard caused by metallic lithium dendrite grown on graphite anode at high rates [30]. Thus it can be seen the graphite cannot meet the requirement of lithium-ion batteries with high energy and high power. Therefore, it is necessary to develop high power, high rate capability, low-cost, environmentally friendly and renewable anode electrode materials. 


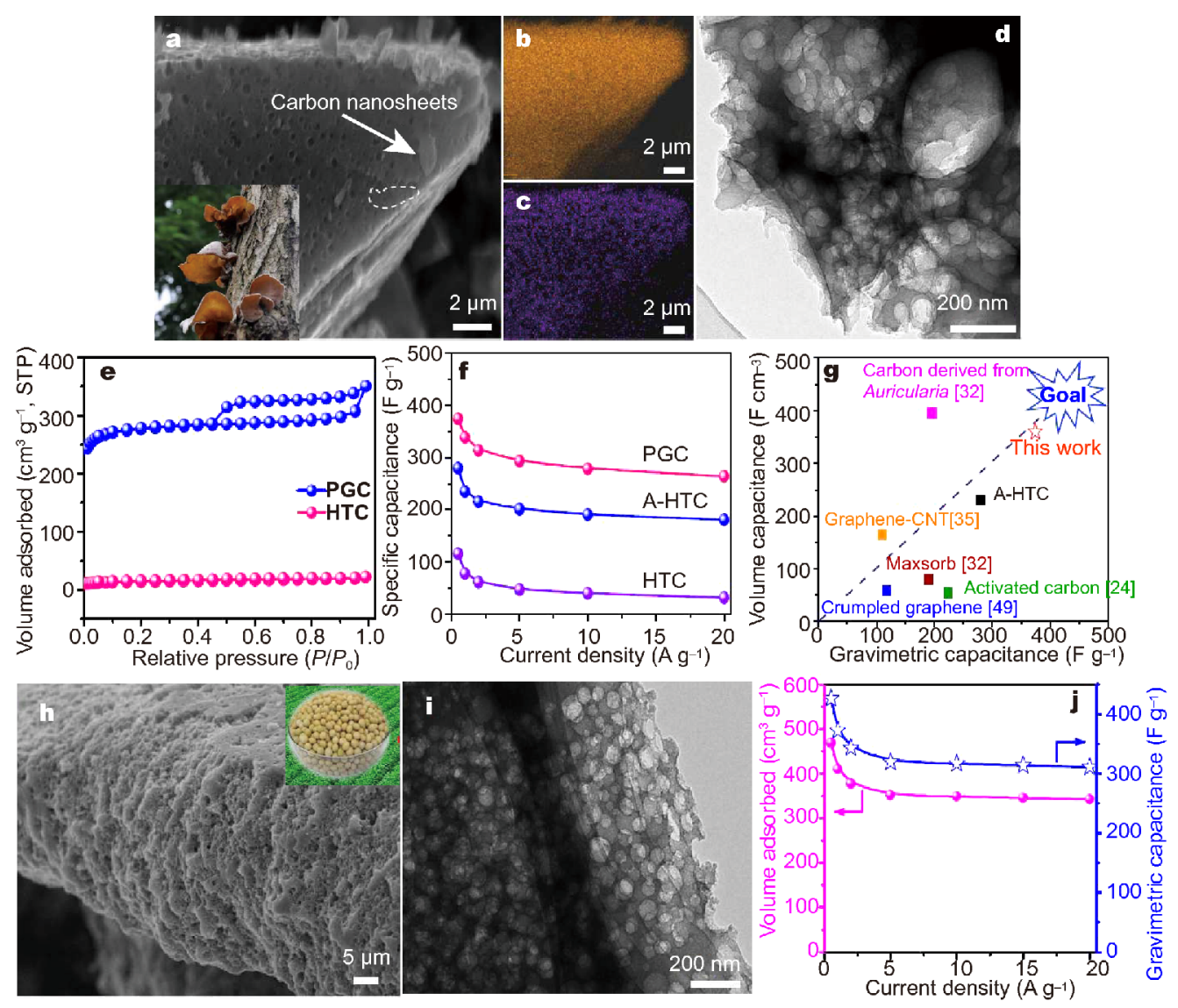

Figure 18 (a) SEM image of the obtained densely porous layer-stacking carbon (PGC) material derived from fungus. (b, c) Corresponding elemental mapping images of $\mathrm{C}$ atom and $\mathrm{O}$ atom in (a). (d) HRTEM image of PGC, showing interconnected porous system. (e) $\mathrm{N}_{2}$ adsorption/desorption isotherm of HTC and PGC. (f) The gravimetric capacitance of HTC, PGC and A-HTC electrodes at the current densities from 0.5 to $20 \mathrm{~A} \mathrm{~g}^{-1}$. (g) Comparison of the volumetric and gravimetric capacitances of PGC electrode with other carbon electrodes in aqueous electrolytes. Reprinted with permission from Ref. [117], Copyright 2016, Elsevier. (h) SEM and TEM (i) images of SBC-600. (j) Gravimetric and volumetric capacitances of SBC600 as a function of current density. Reprinted with permission from Ref. [130], Copyright 2016, Elsevier.

In this regard, biomass-derived carbon materials are a suitable candidate for anode material of lithium-ion batteries, due to their high surface area, adjustable pore structure, excellent conductivity, modifiable surface chemistry and low cost. On the one hand, the functional groups or heteroatoms from biomass itself or dopant result in increasing available active sites and modulate their electronic and chemical properties. On the other hand, the porous biomass-derived carbon can shorten the ion diffusion pathways and offer the increased electrode/ electrolyte interface for the enhanced rate capability. To date, most biomass-derived carbon have been prepared from various biomass precursors and used in anode materials of lithium-ion batteries, such as coir pith [194], cotton [195], wheat stalk $[26,86]$, bean dreg [196], microalgae [197], glucose [198], ramie fibers and corncobs
[57], coconut oil [21], sisal fiber [199], green tea [200], lignin [201].

Although the amorphous biomass-derived carbon could intercalate more $\mathrm{Li}$ and obtain a higher capacity than graphite, the rate performance is still unsatisfactory. Usually, $\mathrm{N}$-doping not only elevates the electrical conductivity of carbon materials, but also increases the active sites of lithium storage. Some researchers used nitrogen rich biomass as carbon and nitrogen sources to prepare anode materials, such as shrimp shells [202], egg yolk [149], honeysuckle [121], ginkgo leave [203], ox horns [204], hair [205], wheat straw [206]. Chen et al. [206] reported hierarchically porous nitrogen-rich carbon (HPNC) derived from wheat straw through acid pretreatment followed by $\mathrm{KOH}$-activation process. The resulting material exhibited a thin pore walls structure with 


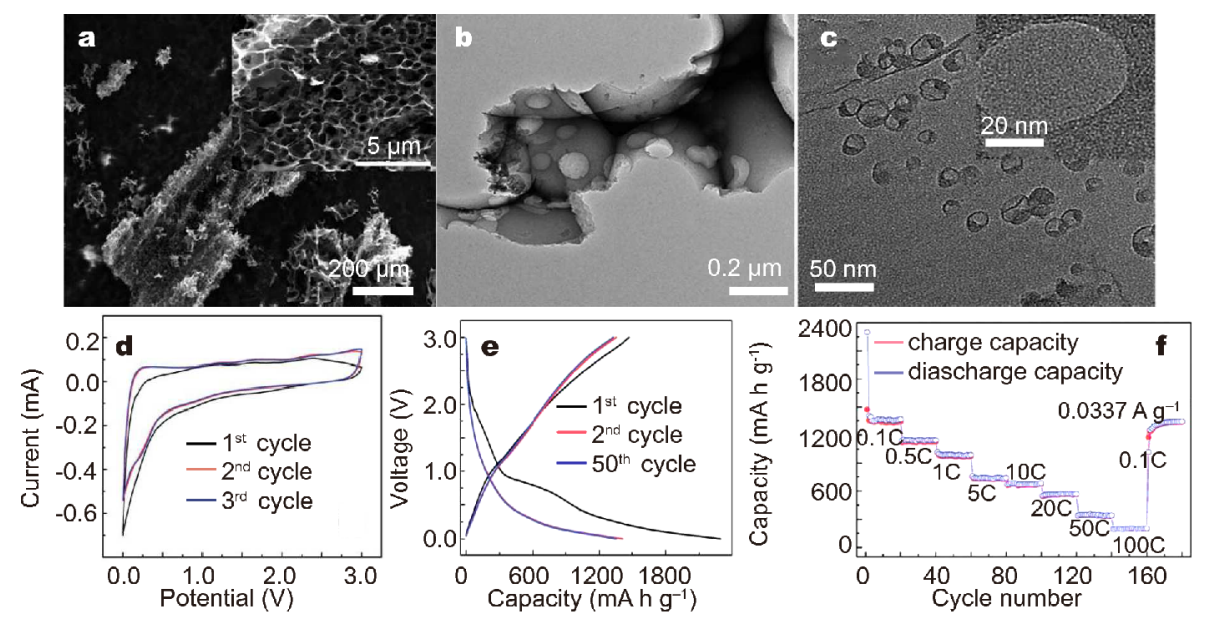

Figure 19 (a) SEM and (b and c) TEM images of the hierarchically porous nitrogen-rich carbon (HPNC). (d) Cyclic voltammograms of the HPNC at a scan rate of $0.1 \mathrm{mV} \mathrm{s}^{-1}$. (e) Charge and discharge curves of the HPNC at $0.037 \mathrm{~A} \mathrm{~g}^{-1}$. (f) The capacity of the HPNC over cycling at different rates. Reprinted with permission from Ref. [206], Copyright 2014, Royal Society of Chemistry.

nitrogen content of up to $5.13 \%$ (Fig. 19a-c). The HPNC used as an anode for lithium-ion batteries shows a superior specific capacity of $1470 \mathrm{~mA} \mathrm{~h} \mathrm{~g}^{-1}$ at $0.037 \mathrm{~A} \mathrm{~g}^{-1}$, and possesses an ultrahigh rate capability of $344 \mathrm{~mA} \mathrm{~h} \mathrm{~g}^{-1}$ at $18.5 \mathrm{~A} \mathrm{~g} \mathrm{~g}^{-1}$. Even at an extremely high current density of $37 \mathrm{~A} \mathrm{~g}^{-1}$, the reversible capacity is still as high as $198 \mathrm{~mA}$ $\mathrm{h} \mathrm{g}^{-1}$ (Fig. 19d-f). Ou et al. [121] reported a hierarchical porous N, S-codoped carbon (HPC) with high SSA (830 $\left.\mathrm{m}^{2} \mathrm{~g}^{-1}\right)$ and pore volume $\left(0.53 \mathrm{~cm}^{3} \mathrm{~g}^{-1}\right)$ by $\mathrm{KOH}$ activating honeysuckle. The contents of $\mathrm{N}$ and $\mathrm{S}$ of HPC material are $1.55 \%$ and $0.54 \%$, respectively, which is ascribed to honeysuckle inherently rich in nitrogen and sulfur heteroatoms. The HPC as an anode for lithium ion battery displayed a reversible charging capacity of $1310 \mathrm{~mA} \mathrm{~h} \mathrm{~g}^{-1}$ at $0.1 \mathrm{~A} \mathrm{~g}^{-1}$ and excellent rate capability $\left(370 \mathrm{~mA} \mathrm{~h} \mathrm{~g}^{-1}\right.$ at $\left.20 \mathrm{~A} \mathrm{~g}^{-1}\right)$. It is worth mentioning that heteroatom-doping and reasonable pore structure is conducive to improving the electrochemical performances of lithium-ion batteries.

In order to control the pore size, introducing templates seems to be an optional route to prepare porous biomassderived carbon materials for lithium-ion batteries. For example, Li et al. [137] prepared mesoporous nitrogenrich carbon by egg white proteins as carbon precursor and mesoporous cellular foam silica as template. The obtained mesoporous carbon shows pores size at 20-30 $\mathrm{nm}$, a surface area of $805.7 \mathrm{~m}^{2} \mathrm{~g}^{-1}$ and a high $\mathrm{N}$-content of $10.1 \mathrm{wt} \%$. The resulting mesoporous nitrogen-rich carbon as the anode exhibited a reversible lithium storage capacity of $1780 \mathrm{~mA} \mathrm{~h} \mathrm{~g}^{-1}$. Zhu et al. [195] prepared porous carbon, derived from cotton cellulose using $\mathrm{MgO}$ as template, exhibiting a SSA as high as $1260 \mathrm{~m}^{2} \mathrm{~g}^{-1}$ and macro/mesoporous structure (Fig. 20a-c). The carbon as the anode for lithium-ion battery showed a high reversible capacity of $793 \mathrm{~mA} \mathrm{~h} \mathrm{~g}^{-1}$ at $0.5 \mathrm{~A} \mathrm{~g}^{-1}$ after 500 cycles and high-rate capability (Fig. $20 \mathrm{~d}-\mathrm{g}$ ). In general, as anode materials of lithium-ion batteries, the superior specific capacity and excellent rate performance of biomass-derived carbon materials could be assigned to following reasons: (1) the hierarchical micro-/meso-/macropores structure offers short ion transport pathways and accelerates the kinetic process of ion diffusion in the electrodes, improving the rate performance; (2) the interconnected pores form a continuous conductive network decreasing electron transport resistance; (3) high surface area can greatly enhance contact area between electrode and electrolyte for charge-transfer reaction, improving the lithium-ion storage capacity; (4) high nitrogen content can provide strong electronegativity and more active sites, which facilitates the interaction of lithium-ions in the carbon, enhancing the electronic conductivity and electrochemical stability of biomass-derived carbon materials.

Some scientists have paid attention to some high capacity anode materials, such as $\mathrm{Si}$, Sn, and transition metal oxides. However, these materials usually suffer from poor conductivity and severe volume changes during the charge/discharge processes, resulting in the rapid capacity decay of lithium-ion battery. Thus, a number of renewable biomass-based carbon composites materials have been used in anode materials of lithium-ion batteries, such as rice husk derived C/Si composites [207], 

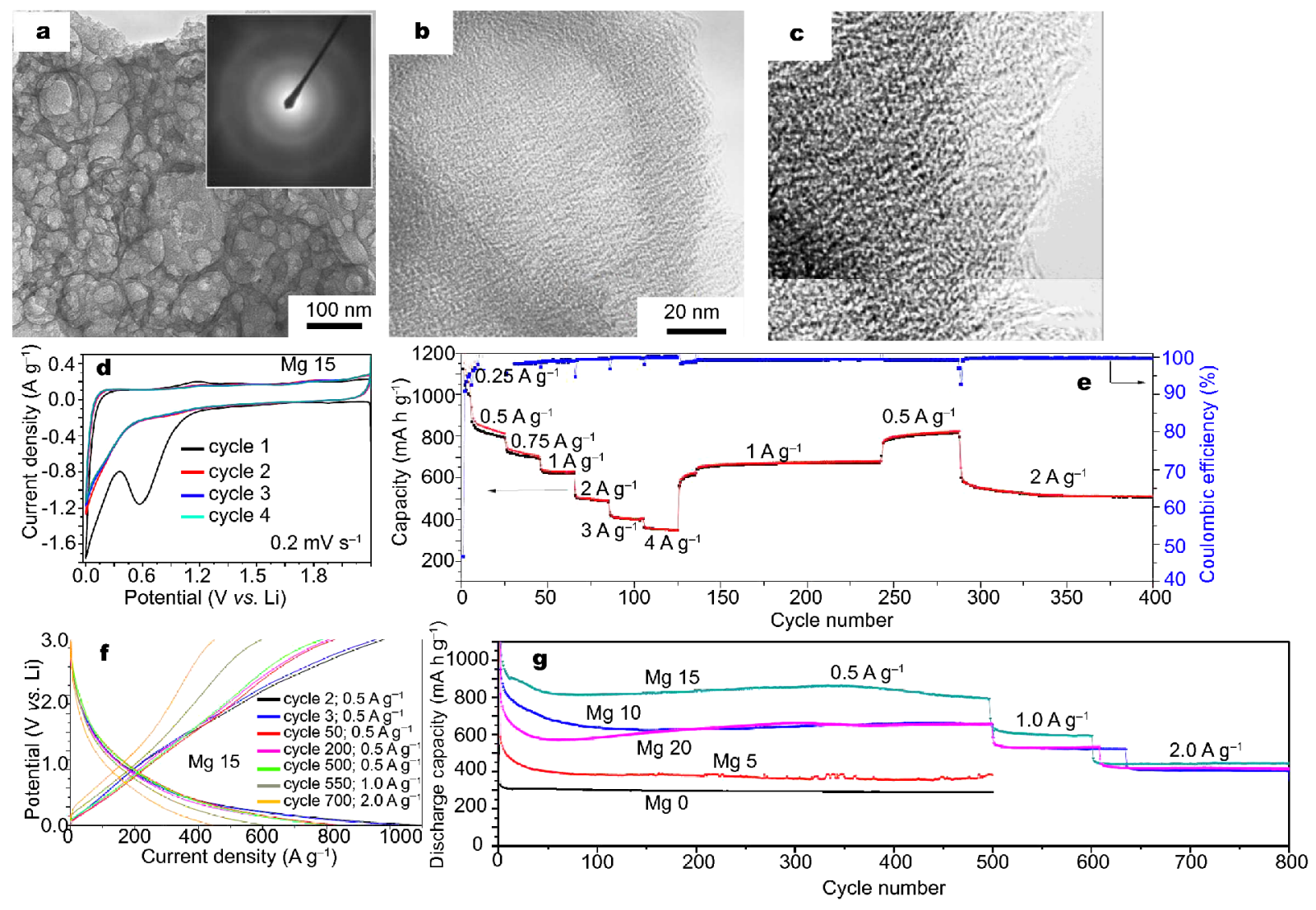

Figure 20 (a) TEM and (b, c) high-resolution TEM images for sample Mg15. (d) CV curves of samples Mg15. (e) Rate capabilities and cycle performance of sample Mg15 cycled at different current rates. (f) Galvanostatic charge-discharge of Mg15. (g) Cycling performance of the synthesized carbon samples. Reprinted with permission from Ref. [195], Copyright 2016, Royal Society of Chemistry.

$\mathrm{MoO}_{2}$ /seaweed-derived carbon [208], $\mathrm{Co}_{3} \mathrm{O}_{4} /$ murdannia simplex-derived carbon [209], $\mathrm{CoMoS}_{3.13} /$ alginate-derived carbon [210], $\mathrm{MoS}_{2} /$ auricularia-derived carbon [118], $\mathrm{ZnMn}_{2} \mathrm{O}_{4} /$ microalgaes-derived carbon [211], $\mathrm{Fe}_{2} \mathrm{O}_{3} /$ bacterial cellulose-derived carbon [71], $\mathrm{Mn}_{2} \mathrm{O}_{3}$ /human hairderived carbon [212], $\mathrm{MnO} /$ auricularia-derived carbon [213], NiO/lotus pollen grains-derived carbon [214]. These biomass-based carbon composites materials with ultrahigh capacity not only provide high conductive substrate, but also buffer the stress of the volume changes keeping the structural integrity during charging and discharging process.

Biomass-derived carbon materials for sodium-ion batteries In contrast to lithium-ion batteries, sodium-ion batteries have attracted a great deal of attention over last few years because of their wider availability, rich sodium resource, low cost and similar insertion chemistry property. However, the development of the anode materials of sodiumion batteries with high sodium storage performance re- mains a huge challenge due to the sodium-ion with larger ionic radius cannot be easily intercalated into the commercial graphite interlayers. Accordingly, among various types of carbon materials, hard carbon-based materials are considered a promising anode candidate for sodiumion batteries, owing to their large interlayer distance, non-ordered structure, high reversible capacity, low average potential, long cycling stability and low cost. Hard carbon materials are commonly produced from the pyrolysis of polymers, meanwhile they can also be derived from a variety of biomass precursors, such as sucrose [37], glucose [39], lotus petioles [145], coconut oil [21], ramie fibers and corncobs [57], corn cobs [215], horn comb [216], bacterial cellulose [70], oatmeal [22], maize [217], okara [96], dandelion [76], grass [218], black fungus [219]. However, hard carbon anode materials exhibited a low initial Coulombic efficiency due to the formation of solid electrolyte interface (SEI) layer. Thus, it is necessary to reduce the contact area of a carbon anode with electrolyte for addressing this problem. 

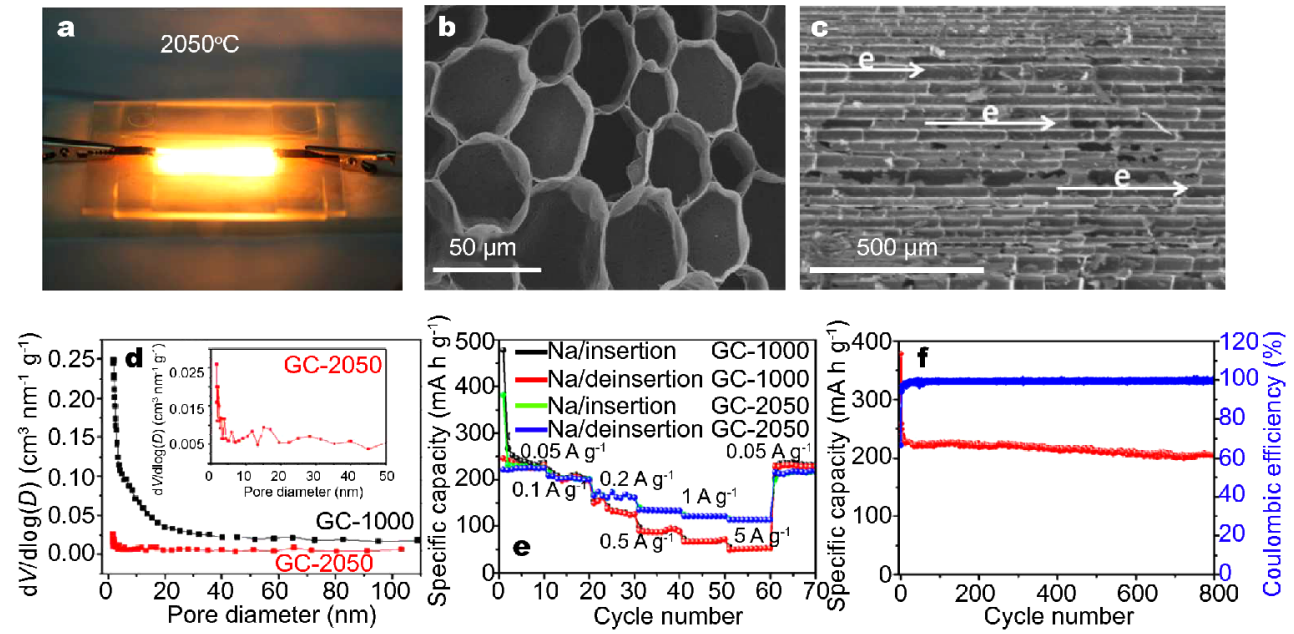

Figure 21 (a) Digital photograph of switchgrass derived carbon under Joule heating. (b) SEM image of cross section from GC-2050, highlighting the hollow structure formed by extremely thin cell wall. (c) SEM image of longitudinal section from GC-2050, highlighting the parallel array structure of channel. (d) the pore size distribution curve of GC-1000 and GC-2050 (inset is the enlarged view of GC-2050). (e) The rate performances and (f) longterm cycling stability (current rate: $50 \mathrm{~mA} \mathrm{~g}^{-1}$ ) of switchgrass derived carbon anode GC-1000 and GC-2050. Reprinted with permission from Ref. [218], Copyright 2017, American Chemical Society.

Dahbi et al. [220] synthesized hard carbon by the carbonization of argan shell biomass. The results showed that the sodiation capacity varied within $5 \%$, but the desodiation capacity increased from 232 to $300 \mathrm{~mA} \mathrm{~h} \mathrm{~g}^{-1}$ along with the initial Coulombic efficiency from 66.2 to $83.9 \%$ at the carbonization temperatures from 800 to $1300^{\circ} \mathrm{C}$. The temperature-dependent increased graphitization degree, the decreased SSA and total pore volume of hard carbon are responsible for high Coulombic efficiency. In addition, it is very important to design reasonable pore structure for the anode materials of sodiumion batteries. Zhang et al. [218] prepared three-dimensional porous hierarchical carbon architecture using switchgrass as carbon source at $2050^{\circ} \mathrm{C}$, showing a highperformance anode material for sodium-ion batteries. The as-obtained carbon intrinsically inherited porous hierarchical structure of switchgrass (Fig. 21a-c), and showed an average interlayer spacing of $0.376 \mathrm{~nm}$. The SSA of porous carbon carbonized at $1000^{\circ} \mathrm{C}$ (GC-1000) was $619.8 \mathrm{~m}^{2} \mathrm{~g}^{-1}$, but SSA of GC-2050 treated at $2050^{\circ} \mathrm{C}$ decreased to be $23.1 \mathrm{~m}^{2} \mathrm{~g}^{-1}$ due to the improved graphitic crystallinity. Although the SSA of grass derived carbon decreased after Joule heating, its porosity with a large quantity of mesopores and micropores retained (Fig. 21d), which would facilitate the penetration of electrolyte into carbon surface, thus shortening the sodium-ion diffusion distance. As a result, the GC-2050 exhibited an enhanced rate capability and outstanding cycling stability with capacity retention of up to $87 \%$ after 800 cycles (Fig. 21e, f).
Heteroatom doping commonly attract more attention, which can modify the surface properties and texture of carbon materials, to increase the carbon interlayer distance. Hao et al. [92] reported a high sulfur doped (8.245 $\mathrm{wt} \%)$ porous carbon derived from ginkgo leaves by hydrothermal treatment in sulfur acid solution. It had the capacity of $200 \mathrm{~mA} \mathrm{~h} \mathrm{~g}^{-1}$ after 500 cycles ( $99 \%$ of capacity retention) at $0.2 \mathrm{~A} \mathrm{~g}^{-1}$. The introduction of $\mathrm{S}$ atom into carbon structure can increase carbon interlayer distance, which not only provides the amount of active sites to store sodium-ions, but also synchronously accelerates sodium-ion insertion/de-insertion, further enhancing electrode kinetics. Moreover, the common nitrogen and phosphorous doping/co-doping can also play the same role [39]. The large interlayer distance after heteroatom doping facilitates the transport and storage of sodiumions inside the biomass-derived carbon materials, which results in the high rate performance for sodium-ion batteries.

In general, the biomass-derived carbon acts as sodiumion battery anode materials, exhibiting excellent electrochemical performances, which can be ascribed to the following points: (1) more reversible sodium storage active sites, which can improve the storage capacity of sodium-ions; (2) the special porous structure, which can shorten sodium-ion diffusion distance increasing the rate capability; (3) the enlarged interlayer space, which can facilitate the insertion/de-insertion sodium-ions; (4) the altered electronic state caused by heteroatom doping is conducive to the adsorption of electrolyte ions; (5) the 
optimized carbonization temperature and using a reasonable electrolyte can tailor the formation of SEI films and improve the initial Coulombic efficiency.

\section{CONCLUSIONS AND OUTLOOK}

The biomass-derived carbons are considered the next generation of electrode materials for energy storage devices due to their rich resources, environmental friendliness and adjustable physical/chemical properties. Importantly, sustainable biomass energy is more urgently needed now than ever before, not least to alleviate the tense oil resources. Therefore, we should vigorously advocate the use of waste and rich biomass as a carbon source, instead of costly and rare biomass even food. Moreover, the design of biomass-derived carbon materials with appropriate structure and surface chemistry property is very important for the applications in energy storage devices. In this review, we have presented the effect of the pore structure, surface area and heteroatom doping on the electrochemical properties as well as the general synthetic method for biomass-derived carbon materials. The advanced applications on the basis of biomass-derived carbon in energy storage devices, mainly the use in supercapacitors, lithium-ion batteries and sodium-ion batteries, have been also discussed.

Although some progress in biomass-derived carbon materials for the field of energy storage has been made, there are still some challenges limiting their further application: (1) Biomass-derived carbon with different structures should be adapted to different energy storage devices according to different energy storage mechanisms. (2) The structure and surface chemistry of biomassderived carbon materials should be reasonably regulated and controlled. For example, the high SSA is usually derived from the chemical activation method, resulting in a large number of micropores. However, these micropores are not conducive to the diffusion and transmission of electrolyte ions, resulting in poor power characteristics. Furthermore, the porous structure in carbon materials may suffer collapse when the large surface area is overly pursued, leading to the difficulty of ion and electron transport, especially for supercapacitors. (3) The use of heteroatom can modify the surface of the carbon material to increase the interlayer spacing and active sites, which can be beneficial for the intercalation and deintercalation of lithium/sodium ions in the application of lithium (sodium)-ion batteries. However, some heteroatoms may decrease the electrical conductivity of carbon materials, such as oxygen and sulfur containing functional groups. (4) Currently, biomass-derived carbon materials serve as a support skeleton to load high pseudo-capacitance materials due to their good electronic conductivity and large SSA. However, how to solve the problem of interface combination is particularly important. (5) It is necessary to expand the scale of production for biomass-derived carbon materials from the current laboratory stage to the real industrial applications. A simple and green preparation process should be deeply investigated to obtain low cost and environmental friendliness. In a word, these contradictory problems in the material structure should be balanced to provide guidance for the design of high electrochemical performance electrode materials.

Future research should be directed towards the development of all biomass-based energy storage devices by taking full advantage of the structural diversity of biomass to achieve sustainable development strategies. Moreover, some of the emerging electrodes, such as ultra-microelectrode, flexible electrode, monolithic solid electrode, wearable electrode, can also be strongly advocated to use biomass-derived carbon materials with unique structure. For example, biomass-derived carbon materials with 1D fibrous structure can be assembled into a garment to make a wearable electrode. Biomass-derived carbon materials with $2 \mathrm{D}$ lamellar structure are easy to fabricate films for flexible electrode. Biomass-derived carbon materials with 3D skeleton structure can load high electrochemical performance materials to make monolithic electrode. In addition, biomass-derived carbon materials have also been developed in other areas, such as lithium sulfur battery, fuel cell, electocatalysis, biomedicine, sensor device. When more researchers are devoting everincreasing efforts to the search for biomass energy, we are strongly convinced that the next generation biomass-derived carbon materials will bring more exciting results.

Received 11 October 2017; accepted 27 November 2017; published online 27 December 2017

1 Chen X, Li C, Grätzel $\mathrm{M}$, et al. Nanomaterials for renewable energy production and storage. Chem Soc Rev, 2012, 41: 79097937

2 Wang H, Yang Y, Guo L. Renewable-biomolecule-based electrochemical energy-storage materials. Adv Energy Mater, 2017, 7: 1700663

3 Liu J, Cao H, Jiang B, et al. Newborn 2D materials for flexible energy conversion and storage. Sci China Mater, 2016, 59: 459474

4 Zhang Y, Liu X, Wang S, et al. Bio-nanotechnology in highperformance supercapacitors. Adv Energy Mater, 2017, 7: 1700592

5 Enock TK, King'ondu CK, Pogrebnoi A, et al. Status of biomass derived carbon materials for supercapacitor application. Int $\mathrm{J}$ Electrochem, 2017, 2017: 1-14 
6 Zhang S, Pan N. Supercapacitors performance evaluation. Adv Energy Mater, 2015, 5: 1401401

7 Wu Z, Zhang X. N, O-codoped porous carbon nanosheets for capacitors with ultra-high capacitance. Sci China Mater, 2016, 59: 547-557

8 Tang W, Zhang Y, Zhong Y, et al. Natural biomass-derived carbons for electrochemical energy storage. Mater Res Bull, 2017, 88: 234-241

9 Hou H, Qiu X, Wei W, et al. Carbon anode materials for advanced sodium-ion batteries. Adv Energy Mater, 2017, 114: 1602898

10 Liu H, Liu X, Li W, et al. Porous carbon composites for next generation rechargeable lithium batteries. Adv Energy Mater, 2017, 414: 1700283

11 Béguin F, Presser V, Balducci A, et al. Carbons and electrolytes for advanced supercapacitors. Adv Mater, 2014, 26: 2219-2251

12 Zhang X, Zhang H, Lin Z, et al. Recent advances and challenges of stretchable supercapacitors based on carbon materials. Sci China Mater, 2016, 59: 475-494

13 Wen L, Li F, Cheng HM. Carbon nanotubes and graphene for flexible electrochemical energy storage: from materials to devices. Adv Mater, 2016, 28: 4306-4337

14 Guo X, Zheng S, Zhang G, et al. Nanostructured graphene-based materials for flexible energy storage. Energy Storage Mater, 2017, 9: $150-169$

15 Zheng S, Wu ZS, Wang S, et al. Graphene-based materials for high-voltage and high-energy asymmetric supercapacitors. Energy Storage Mater, 2017, 6: 70-97

16 Wu H, Zhang Y, Cheng L, et al. Graphene based architectures for electrochemical capacitors. Energy Storage Mater, 2016, 5: 8-32

17 Dai H. Carbon nanotubes: synthesis, integration, and properties. Acc Chem Res, 2002, 35: 1035-1044

18 Hummers Jr. WS, Offeman RE. Preparation of graphitic oxide. J Am Chem Soc, 1958, 80: 1339-1339

19 Shao Y, El-Kady MF, Wang LJ, et al. Graphene-based materials for flexible supercapacitors. Chem Soc Rev, 2015, 44: 3639-3665

20 Imtiaz S, Zhang J, Zafar ZA, et al. Biomass-derived nanostructured porous carbons for lithium-sulfur batteries. Sci China Mater, 2016, 59: 389-407

21 Gaddam RR, Yang D, Narayan R, et al. Biomass derived carbon nanoparticle as anodes for high performance sodium and lithium ion batteries. Nano Energy, 2016, 26: 346-352

22 Yan D, Yu C, Zhang X, et al. Nitrogen-doped CMs derived from oatmeal as high capacity and superior long life anode material for sodium ion battery. Electrochim Acta, 2016, 191: 385-391

23 Ogale AA, Zhang M, Jin J. Recent advances in carbon fibers derived from biobased precursors. J Appl Polym Sci, 2016, 133: 43794

24 Lai F, Miao YE, Zuo L, et al. Biomass-derived nitrogen-doped carbon nanofiber network: a facile template for decoration of ultrathin nickel-cobalt layered double hydroxide nanosheets as high-performance asymmetric supercapacitor electrode. Small, 2016, 12: 3235-3244

$25 \mathrm{Yu} \mathrm{H}$, Zhang W, Li T, et al. Capacitive performance of porous carbon nanosheets derived from biomass cornstalk. RSC Adv, 2017, 7: 1067-1074

26 Zhou X, Chen F, Bai $\mathrm{T}$, et al. Interconnected highly graphitic carbon nanosheets derived from wheat stalk as high performance anode materials for lithium ion batteries. Green Chem, 2016, 18 : 2078-2088
27 Zhang W, Lin H, Lin Z, et al. 3D hierarchical porous carbon for supercapacitors prepared from lignin through a facile templatefree method. ChemSusChem, 2015, 8: 2114-2122

28 Fan YM, Song WL, Li X, et al. Assembly of graphene aerogels into the $3 \mathrm{D}$ biomass-derived carbon frameworks on conductive substrates for flexible supercapacitors. Carbon, 2017, 111: 658-666

29 Wu XL, Wen T, Guo HL, et al. Biomass-derived sponge-like carbonaceous hydrogels and aerogels for supercapacitors. ACS Nano, 2013, 7: 3589-3597

30 Deng J, Li M, Wang Y. Biomass-derived carbon: synthesis and applications in energy storage and conversion. Green Chem, 2016, 18: 4824-4854

31 Wang J, Nie P, Ding B, et al. Biomass derived carbon for energy storage devices. J Mater Chem A, 2017, 5: 2411-2428

32 Chen Y, Shi J. Mesoporous carbon biomaterials. Sci China Mater, 2015, 58: 241-257

33 Zheng X, Luo J, Lv W, et al. Two-dimensional porous carbon: synthesis and ion-transport properties. Adv Mater, 2015, 27: 5388-5395

34 Liu B, Liu Y, Chen $\mathrm{H}$, et al. Oxygen and nitrogen co-doped porous carbon nanosheets derived from Perilla frutescens for high volumetric performance supercapacitors. J Power Sources, 2017, 341: 309-317

35 Ling Z, Wang Z, Zhang M, et al. Sustainable synthesis and assembly of biomass-derived $\mathrm{B} / \mathrm{N}$ Co-doped carbon nanosheets with ultrahigh aspect ratio for high-performance supercapacitors. Adv Funct Mater, 2016, 26: 111-119

36 Gao Z, Zhang Y, Song N, et al. Biomass-derived renewable carbon materials for electrochemical energy storage. Mater Res Lett, 2016, 5: 69-88

37 Li Y, Xu S, Wu X, et al. Amorphous monodispersed hard carbon micro-spherules derived from biomass as a high performance negative electrode material for sodium-ion batteries. J Mater Chem A, 2015, 3: 71-77

38 Gong Y, Xie L, Li H, et al. Sustainable and scalable production of monodisperse and highly uniform colloidal carbonaceous spheres using sodium polyacrylate as the dispersant. Chem Commun, 2014, 50: 12633-12636

39 Li Y, Wang Z, Li L, et al. Preparation of nitrogen- and phosphorous co-doped CMs and their superior performance as anode in sodium-ion batteries. Carbon, 2016, 99: 556-563

40 Zhao Y, Meng Y, Jiang P. Carbon@ $\mathrm{MnO}_{2}$ core-shell nanospheres for flexible high-performance supercapacitor electrode materials. J Power Sources, 2014, 259: 219-226

41 Falco C, Baccile N, Titirici MM. Morphological and structural differences between glucose, cellulose and lignocellulosic biomass derived hydrothermal carbons. Green Chem, 2011, 13: 3273-3281

42 Górka J, Vix-Guterl C, Matei Ghimbeu C. Recent progress in design of biomass-derived hard carbons for sodium ion batteries. C, 2016, 2: 24

43 Liu Y, Cai X, Luo B, et al. $\mathrm{MnO}_{2}$ decorated on carbon sphere intercalated graphene film for high-performance supercapacitor electrodes. Carbon, 2016, 107: 426-432

44 Fan Y, Liu PF, Yang ZJ, et al. Bi-functional porous carbon spheres derived from pectin as electrode material for supercapacitors and support material for $\mathrm{Pt}$ nanowires towards electrocatalytic methanol and ethanol oxidation. Electrochim Acta, 2015, 163: 140148

45 Mao C, Liu S, Pang L, et al. Ultrathin $\mathrm{MnO}_{2}$ nanosheets grown on fungal conidium-derived hollow carbon spheres as supercapacitor 
electrodes. RSC Adv, 2016, 6: 5184-5191

46 Yu YN, Wang MQ, Bao SJ. Biomass-derived synthesis of nitrogen and phosphorus co-doped mesoporous carbon spheres as catalysts for oxygen reduction reaction. J Solid State Electrochem, 2016, 21: 103-110

47 Tang $\mathrm{H}$, Wang $\mathrm{M}, \mathrm{Lu} \mathrm{T}$, et al. Porous carbon spheres as anode materials for sodium ion batteries with high capacity and long cycling life. Ceramics Int, 2017, 43: 4475-4482

48 Gao S, Chen Y, Fan H, et al. Large scale production of biomassderived $\mathrm{N}$-doped porous carbon spheres for oxygen reduction and supercapacitors. J Mater Chem A, 2014, 2: 3317-3324

49 Duan B, Gao X, Yao X, et al. Unique elastic N-doped carbon nanofibrous microspheres with hierarchical porosity derived from renewable chitin for high rate supercapacitors. Nano Energy, 2016, 27: 482-491

50 Falco C, Sieben JM, Brun N, et al. Hydrothermal carbons from hemicellulose-derived aqueous hydrolysis products as electrode materials for supercapacitors. ChemSusChem, 2013, 6: 374-382

51 Tang K, Fu L, White RJ, et al. Hollow carbon nanospheres with superior rate capability for sodium-based batteries. Adv Energy Mater, 2012, 2: 873-877

52 Tang K, White RJ, Mu X, et al. Hollow carbon nanospheres with a high rate capability for lithium-based batteries. ChemSusChem, 2012, 5: 400-403

53 Jin Y, Tian K, Wei L, et al. Hierarchical porous microspheres of activated carbon with a high surface area from spores for electrochemical double-layer capacitors. J Mater Chem A, 2016, 4: 15968-15979

54 Wei X, Li Y, Gao S. Biomass-derived interconnected carbon nanoring electrochemical capacitors with high performance in both strongly acidic and alkaline electrolytes. J Mater Chem A, 2017, 5: 181-188

55 He S, Chen W. Application of biomass-derived flexible carbon cloth coated with $\mathrm{MnO}_{2}$ nanosheets in supercapacitors. J Power Sources, 2015, 294: 150-158

$56 \mathrm{Hu}$ X, Xiong W, Wang W, et al. Hierarchical manganese dioxide/ poly(3,4-ethylenedioxythiophene) core-shell nanoflakes on ramie-derived carbon fiber for high-performance flexible all-solidstate supercapacitor. ACS Sustain Chem Eng, 2016, 4: 1201-1211

57 Jiang $\mathrm{Q}$, Zhang Z, Yin S, et al. Biomass carbon micro/nanostructures derived from ramie fibers and corncobs as anode materials for lithium-ion and sodium-ion batteries. Appl Surf Sci, 2016, 379: 73-82

58 Wei T, Wei X, Gao Y, et al. Large scale production of biomassderived nitrogen-doped porous carbon materials for supercapacitors. Electrochim Acta, 2015, 169: 186-194

59 Liu B, Zhou X, Chen $\mathrm{H}$, et al. Promising porous carbons derived from lotus seedpods with outstanding supercapacitance performance. Electrochim Acta, 2016, 208: 55-63

60 Long C, Qi D, Wei T, et al. Nitrogen-doped carbon networks for high energy density supercapacitors derived from polyaniline coated bacterial cellulose. Adv Funct Mater, 2014, 24: 3953-3961

61 Shan D, Yang J, Liu W, et al. Biomass-derived three-dimensional honeycomb-like hierarchical structured carbon for ultrahigh energy density asymmetric supercapacitors. J Mater Chem A, 2016, 4: $13589-13602$

62 Hao X, Wang J, Ding B, et al. Bacterial-cellulose-derived interconnected meso-microporous carbon nanofiber networks as binder-free electrodes for high-performance supercapacitors. J Power Sources, 2017, 352: 34-41
63 Jiang Y, Yan J, Wu X, et al. Facile synthesis of carbon nanofibersbridged porous carbon nanosheets for high-performance supercapacitors. J Power Sources, 2016, 307: 190-198

64 Wang X, Kong D, Zhang Y, et al. All-biomaterial supercapacitor derived from bacterial cellulose. Nanoscale, 2016, 8: 9146-9150

65 Zhao PY, Guo Y, Yu BJ, et al. Biotechnology humic acids-based electrospun carbon nanofibers as cost-efficient electrodes for lithium-ion batteries. Electrochim Acta, 2016, 203: 66-73

66 Dallmeyer I, Lin LT, Li Y, et al. Preparation and characterization of interconnected, kraft lignin-based carbon fibrous materials by electrospinning. Macromol Mater Eng, 2014, 299: 540-551

67 Berenguer R, García-Mateos FJ, Ruiz-Rosas R, et al. Biomassderived binderless fibrous carbon electrodes for ultrafast energy storage. Green Chem, 2016, 18: 1506-1515

68 Li D, Lv C, Liu L, et al. Egg-box structure in cobalt alginate: a new approach to multifunctional hierarchical mesoporous n-doped carbon nanofibers for efficient catalysis and energy storage. ACS Cent Sci, 2015, 1: 261-269

69 Qiu H, Wang Y, Liu Y, et al. Synthesis of $\mathrm{Co} / \mathrm{Co}_{3} \mathrm{O}_{4}$ nanoparticles embedded in porous carbon nanofibers for high performance lithium-ion battery anodes. J Porous Mater, 2016, 24: 551-557

70 Wang M, Yang Z, Li W, et al. Superior sodium storage in 3D interconnected nitrogen and oxygen dual-doped carbon network. Small, 2016, 12: 2559-2566

71 Huang $\mathrm{Y}$, Lin $\mathrm{Z}$, Zheng $\mathrm{M}$, et al. Amorphous $\mathrm{Fe}_{2} \mathrm{O}_{3}$ nanoshells coated on carbonized bacterial cellulose nanofibers as a flexible anode for high-performance lithium ion batteries. J Power Sources, 2016, 307: 649-656

72 You J, Li M, Ding B, et al. Crab chitin-based 2D soft nanomaterials for fully biobased electric devices. Adv Mater, 2017, 29: 1606895

73 Liu Y, Shi Z, Gao Y, et al. Biomass-swelling assisted synthesis of hierarchical porous carbon fibers for supercapacitor electrodes. ACS Appl Mater Interfaces, 2016, 8: 28283-28290

74 Cheng P, Li T, Yu H, et al. Biomass-derived carbon fiber aerogel as a binder-free electrode for high-rate supercapacitors. J Phys Chem C, 2016, 120: 2079-2086

75 Shen W, Hu T, Wang P, et al. Hollow porous carbon fiber from cotton with nitrogen doping. ChemPlusChem, 2014, 79: 284-289

76 Wang C, Huang J, Qi H, et al. Controlling pseudographtic domain dimension of dandelion derived biomass carbon for excellent sodium-ion storage. J Power Sources, 2017, 358: 85-92

77 Wei Y. Activated carbon microtubes prepared from plant biomass (poplar catkins) and their application for supercapacitors. Chem Lett, 2014, 43: 216-218

78 Xie L, Sun G, Su F, et al. Hierarchical porous carbon microtubes derived from willow catkins for supercapacitor applications. J Mater Chem A, 2016, 4: 1637-1646

79 Zhang $\mathrm{X}$, Zhang $\mathrm{K}$, Li H, et al. Porous graphitic carbon microtubes derived from willow catkins as a substrate of $\mathrm{MnO}_{2}$ for supercapacitors. J Power Sources, 2017, 344: 176-184

80 Wang K, Yan R, Zhao N, et al. Bio-inspired hollow activated carbon microtubes derived from willow catkins for supercapacitors with high volumetric performance. Mater Lett, 2016, 174: 249-252

81 Li Y, Wang G, Wei T, et al. Nitrogen and sulfur co-doped porous carbon nanosheets derived from willow catkin for supercapacitors. Nano Energy, 2016, 19: 165-175

82 Wang K, Zhao N, Lei S, et al. Promising biomass-based activated carbons derived from willow catkins for high performance su- 
percapacitors. Electrochim Acta, 2015, 166: 1-11

83 Dong $\mathrm{Y}$, Wang W, Quan $\mathrm{H}$, et al. Nitrogen-doped foam-like carbon plate consisting of carbon tubes as high-performance electrode materials for supercapacitors. ChemElectroChem, 2016, 3: 814-821

84 Qu Y, Zan G, Wang J, et al. Preparation of eggplant-derived macroporous carbon tubes and composites of EDMCT/Co $(\mathrm{OH})$ $\left(\mathrm{CO}_{3}\right)_{0.5}$ nano-cone-arrays for high-performance supercapacitors. J Mater Chem A, 2016, 4: 4296-4304

85 Ojha K, Kumar B, Ganguli AK. Biomass derived graphene-like activated and non-activated porous carbon for advanced supercapacitors. J Chem Sci, 2017, 129: 397-404

86 Chen F, Yang J, Bai T, et al. Facile synthesis of few-layer graphene from biomass waste and its application in lithium ion batteries. J Electroanal Chem, 2016, 768: 18-26

87 Wang $\mathrm{H}, \mathrm{Xu} \mathrm{Z}$, Kohandehghan A, et al. Interconnected carbon nanosheets derived from hemp for ultrafast supercapacitors with high energy. ACS Nano, 2013, 7: 5131-5141

88 Sun L, Tian C, Li M, et al. From coconut shell to porous graphene-like nanosheets for high-power supercapacitors. J Mater Chem A, 2013, 1: 6462-6470

89 Tian W, Gao Q, Tan Y, et al. Unusual interconnected graphitized carbon nanosheets as the electrode of high-rate ionic liquid-based supercapacitor. Carbon, 2017, 119: 287-295

90 Mondal AK, Kretschmer K, Zhao Y, et al. Nitrogen-doped porous carbon nanosheets from eco-friendly eucalyptus leaves as high performance electrode materials for supercapacitors and lithium ion batteries. Chem Eur J, 2017, 23: 3683-3690

91 Chen C, Yu D, Zhao G, et al. Three-dimensional scaffolding framework of porous carbon nanosheets derived from plant wastes for high-performance supercapacitors. Nano Energy, 2016, 27: 377-389

92 Hao E, Liu W, Liu S, et al. Rich sulfur doped porous carbon materials derived from ginkgo leaves for multiple electrochemical energy storage devices. J Mater Chem A, 2017, 5: 2204-2214

$93 \mathrm{Wu} \mathrm{K}$, Gao B, Su J, et al. Large and porous carbon sheets derived from water hyacinth for high-performance supercapacitors. RSC Adv, 2016, 6: 29996-30003

94 Xu J, Gao Q, Zhang Y, et al. Preparing two-dimensional microporous carbon from Pistachio nutshell with high areal capacitance as supercapacitor materials. Sci Rep, 2014, 4: 5545

95 Park MH, Yun YS, Cho SY, et al. Waste coffee grounds-derived nanoporous carbon nanosheets for supercapacitors. Carbon Lett, 2016, 19: 66-71

96 Yang T, Qian T, Wang M, et al. A sustainable route from biomass byproduct okara to high content nitrogen-doped carbon sheets for efficient sodium ion batteries. Adv Mater, 2016, 28: 539-545

97 Li Z, Lv W, Zhang C, et al. A sheet-like porous carbon for highrate supercapacitors produced by the carbonization of an eggplant. Carbon, 2015, 92: 11-14

98 Hou J, Cao C, Idrees F, et al. Hierarchical porous nitrogen-doped carbon nanosheets derived from silk for ultrahigh-capacity battery anodes and supercapacitors. ACS Nano, 2015, 9: 2556-2564

99 Wang J, Shen L, Xu Y, et al. Lamellar-structured biomass-derived phosphorus- and nitrogen-co-doped porous carbon for highperformance supercapacitors. New J Chem, 2015, 39: 9497-9503

100 Ling Z, Yu C, Fan X, et al. Freeze-drying for sustainable synthesis of nitrogen doped porous carbon cryogel with enhanced supercapacitor and lithium ion storage performance. Nanotechnology, 2015, 26: 374003
101 An HJ, Kim NR, Song MY, et al. Fallen-leaf-derived microporous pyropolymers for supercapacitors. J Industrial Eng Chem, 2017, 45: 223-228

102 Tian X, Ma H, Li Z, et al. Flute type micropores activated carbon from cotton stalk for high performance supercapacitors. J Power Sources, 2017, 359: 88-96

103 Zhu G, Ma L, Lv H, et al. Pine needle-derived microporous nitrogen-doped carbon frameworks exhibit high performances in electrocatalytic hydrogen evolution reaction and supercapacitors. Nanoscale, 2017, 9: 1237-1243

104 Fan Y, Liu P, Zhu B, et al. Microporous carbon derived from acacia gum with tuned porosity for high-performance electrochemical capacitors. Int J Hydrogen Energy, 2015, 40: 6188-6196

105 Sun F, Gao J, Zhu Y, et al. A high performance lithium ion capacitor achieved by the integration of a $\mathrm{Sn}-\mathrm{C}$ anode and a biomass-derived microporous activated carbon cathode. Sci Rep, 2017, 7: 40990

106 Liang T, Chen C, Li X, et al. Popcorn-derived porous carbon for energy storage and $\mathrm{CO}_{2}$ capture. Langmuir, 2016, 32: 8042-8049

107 Liu C, Han G, Chang Y, et al. Properties of porous carbon derived from cornstalk core in high-performance electrochemical capacitors. ChemElectroChem, 2016, 3: 323-331

108 Qiu X, Wang L, Zhu H, et al. Lightweight and efficient microwave absorbing materials based on walnut shell-derived nano-porous carbon. Nanoscale, 2017, 9: 7408-7418

109 Jiang L, Sheng L, Chen X, et al. Construction of nitrogen-doped porous carbon buildings using interconnected ultra-small carbon nanosheets for ultra-high rate supercapacitors. J Mater Chem A, 2016, 4: 11388-11396

110 Jain A, Xu C, Jayaraman S, et al. Mesoporous activated carbons with enhanced porosity by optimal hydrothermal pre-treatment of biomass for supercapacitor applications. Microporous Mesoporous Mater, 2015, 218: 55-61

111 Liou TH. Development of mesoporous structure and high adsorption capacity of biomass-based activated carbon by phosphoric acid and zinc chloride activation. Chem Eng J, 2010, 158: 129-142

112 Niu J, Shao R, Liang J, et al. Biomass-derived mesopore-dominant porous carbons with large SSA and high defect density as high performance electrode materials for Li-ion batteries and supercapacitors. Nano Energy, 2017, 36: 322-330

113 Feng $\mathrm{H}, \mathrm{Hu} \mathrm{H}$, Dong $\mathrm{H}$, et al. Hierarchical structured carbon derived from bagasse wastes: A simple and efficient synthesis route and its improved electrochemical properties for high-performance supercapacitors. J Power Sources, 2016, 302: 164-173

114 Liu J, Deng Y, Li X, et al. Promising nitrogen-rich porous carbons derived from one-step calcium chloride activation of biomassbased waste for high performance supercapacitors. ACS Sustain Chem Eng, 2016, 4: 177-187

115 Hong X, Hui KS, Zeng Z, et al. Hierarchical nitrogen-doped porous carbon with high surface area derived from endothelium corneum gigeriae galli for high-performance supercapacitor. Electrochim Acta, 2014, 130: 464-469

116 Zhu Z, Jiang H, Guo S, et al. Dual tuning of biomass-derived hierarchical carbon nanostructures for supercapacitors: the role of balanced meso/microporosity and graphene. Sci Rep, 2015, 5: 15936

117 Long C, Chen X, Jiang L, et al. Porous layer-stacking carbon derived from in-built template in biomass for high volumetric performance supercapacitors. Nano Energy, 2015, 12: 141-151 
118 Wang H, Ren D, Zhu Z, et al. Few-layer $\mathrm{MoS}_{2}$ nanosheets incorporated into hierarchical porous carbon for lithium-ion batteries. Chem Eng J, 2016, 288: 179-184

119 Li H, Yuan D, Tang C, et al. Lignin-derived interconnected hierarchical porous carbon monolith with large areal/volumetric capacitances for supercapacitor. Carbon, 2016, 100: 151-157

120 Zhuo H, Hu Y, Tong X, et al. Sustainable hierarchical porous carbon aerogel from cellulose for high-performance supercapacitor and $\mathrm{CO}_{2}$ capture. Industrial Crops Products, 2016, 87: 229-235

121 Ou J, Yang L, Zhang Z, et al. Honeysuckle-derived hierarchical porous nitrogen, sulfur, dual-doped carbon for ultra-high rate lithium ion battery anodes. J Power Sources, 2016, 333: 193-202

122 Tian Z, Xiang M, Zhou J, et al. Nitrogen and oxygen-doped hierarchical porous carbons from algae biomass: direct carbonization and excellent electrochemical properties. Electrochim Acta, 2016, 211: 225-233

$123 \mathrm{Yu} \mathrm{W}$, Wang H, Liu S, et al. N, O-codoped hierarchical porous carbons derived from algae for high-capacity supercapacitors and battery anodes. J Mater Chem A, 2016, 4: 5973-5983

124 Zhang C, Zhu X, Cao M, et al. Hierarchical porous carbon materials derived from sheep manure for high-capacity supercapacitors. ChemSusChem, 2016, 9: 932-937

125 Zhao YQ, Lu M, Tao PY, et al. Hierarchically porous and heteroatom doped carbon derived from tobacco rods for supercapacitors. J Power Sources, 2016, 307: 391-400

126 Yang X, Li C, Chen Y. Hierarchical porous carbon with ultrahigh surface area from corn leaf for high-performance supercapacitors application. J Phys D-Appl Phys, 2017, 50: 055501

127 Cai Y, Luo Y, Xiao Y, et al. Facile synthesis of three-dimensional heteroatom-doped and hierarchical egg-box-like carbons derived from moringa oleifera branches for high-performance supercapacitors. ACS Appl Mater Interfaces, 2016, 8: 33060-33071

128 Paraknowitsch JP, Thomas A. Doping carbons beyond nitrogen: an overview of advanced heteroatom doped carbons with boron, sulphur and phosphorus for energy applications. Energy Environ Sci, 2013, 6: 2839-2855

129 Zhou X, Li H, Yang J. Biomass-derived activated carbon materials with plentiful heteroatoms for high-performance electrochemical capacitor electrodes. J Energy Chem, 2016, 25: 35-40

130 Long C, Jiang L, Wu X, et al. Facile synthesis of functionalized porous carbon with three-dimensional interconnected pore structure for high volumetric performance supercapacitors. Carbon, 2015, 93: 412-420

131 Ouyang T, Cheng K, Gao Y, et al. Molten salt synthesis of nitrogen doped porous carbon: a new preparation methodology for high-volumetric capacitance electrode materials. J Mater Chem A, 2016, 4: 9832-9843

$132 \mathrm{Qu} \mathrm{J}$, Geng C, Lv S, et al. Nitrogen, oxygen and phosphorus decorated porous carbons derived from shrimp shells for supercapacitors. Electrochim Acta, 2015, 176: 982-988

133 Gao F, Qu J, Zhao Z, et al. Nitrogen-doped activated carbon derived from prawn shells for high-performance supercapacitors. Electrochim Acta, 2016, 190: 1134-1141

134 Ma G, Yang Q, Sun K, et al. Nitrogen-doped porous carbon derived from biomass waste for high-performance supercapacitor. Bioresource Tech, 2015, 197: 137-142

135 Alshareef $\mathrm{NH}$, Whitehair $\mathrm{D}$, Xia C. The impact of surface chemistry on bio-derived carbon performance as supercapacitor electrodes. J Electron Mater, 2016, 46: 1628-1636
$136 \mathrm{Wu} \mathrm{X}$, Jiang L, Long C, et al. From flour to honeycomb-like carbon foam: carbon makes room for high energy density supercapacitors. Nano Energy, 2015, 13: 527-536

137 Li Z, Xu Z, Tan X, et al. Mesoporous nitrogen-rich carbons derived from protein for ultra-high capacity battery anodes and supercapacitors. Energy Environ Sci, 2013, 6: 871-878

138 Li J, Liu K, Gao X, et al. Oxygen- and nitrogen-enriched 3D porous carbon for supercapacitors of high volumetric capacity. ACS Appl Mater Interfaces, 2015, 7: 24622-24628

139 Chen $\mathrm{L}, \mathrm{Ji} \mathrm{T}, \mathrm{Mu} \mathrm{L}$, et al. Cotton fabric derived hierarchically porous carbon and nitrogen doping for sustainable capacitor electrode. Carbon, 2017, 111: 839-848

140 Zhao Y, Ran W, He J, et al. Oxygen-rich hierarchical porous carbon derived from artemia cyst shells with superior electrochemical performance. ACS Appl Mater Interfaces, 2015, 7: 1132-1139

141 Zhang LL, Li HH, Shi YH, et al. A novel layered sedimentary rocks structure of the oxygen-enriched carbon for ultrahigh-rateperformance supercapacitors. ACS Appl Mater Interfaces, 2016, 8: 4233-4241

142 Feng W, He P, Ding S, et al. Oxygen-doped activated carbons derived from three kinds of biomass: preparation, characterization and performance as electrode materials for supercapacitors. RSC Adv, 2016, 6: 5949-5956

143 Elmouwahidi A, Zapata-Benabithe Z, Carrasco-Marín F, et al. Activated carbons from $\mathrm{KOH}$-activation of argan (Argania spinosa) seed shells as supercapacitor electrodes. Bioresource Tech, 2012, 111: 185-190

144 Yi J, Qing Y, Wu CT, et al. Lignocellulose-derived porous phosphorus-doped carbon as advanced electrode for supercapacitors. J Power Sources, 2017, 351: 130-137

145 Wang P, Qiao B, Du Y, et al. Fluorine-doped carbon particles derived from lotus petioles as high-performance anode materials for sodium-ion batteries. J Phys Chem C, 2015, 119: 21336-21344

146 Wu L, Buchholz D, Vaalma C, et al. Apple-biowaste-derived hard carbon as a powerful anode material for Na-ion batteries. ChemElectroChem, 2016, 3: 292-298

147 Sun L, Fu Y, Tian C, et al. Isolated boron and nitrogen sites on porous graphitic carbon synthesized from nitrogen-containing chitosan for supercapacitors. ChemSusChem, 2014, 7: 1637-1646

148 Xu G, Han J, Ding B, et al. Biomass-derived porous carbon materials with sulfur and nitrogen dual-doping for energy storage. Green Chem, 2015, 17: 1668-1674

149 Zhao H, Gao Y, Wang J, et al. Egg yolk-derived phosphorus and nitrogen dual doped nano carbon capsules for high-performance lithium ion batteries. Mater Lett, 2016, 167: 93-97

150 Ioannidou O, Zabaniotou A. Agricultural residues as precursors for activated carbon production-a review. Renew Sustain Energy Rev, 2007, 11: 1966-2005

151 Wang K, Cao Y, Wang X, et al. Rod-shape porous carbon derived from aniline modified lignin for symmetric supercapacitors. J Power Sources, 2016, 307: 462-467

152 Wang , Wang Q, Zhang G, et al. Promising activated carbons derived from cabbage leaves and their application in high-performance supercapacitors electrodes. J Solid State Electrochem, 2015, 20: 319-325

$153 \mathrm{Wu} \mathrm{K}, \mathrm{Fu} \mathrm{J}$, Zhang X, et al. Three-dimensional flexible carbon electrode for symmetrical supercapacitors. Mater Lett, 2016, 185: 193-196

154 Fan Z, Qi D, Xiao Y, et al. One-step synthesis of biomass-derived 
porous carbon foam for high performance supercapacitors. Mater Lett, 2013, 101: 29-32

155 Bommier C, Xu R, Wang W, et al. Self-activation of cellulose: a new preparation methodology for activated carbon electrodes in electrochemical capacitors. Nano Energy, 2015, 13: 709-717

156 Biswal M, Banerjee A, Deo M, et al. From dead leaves to high energy density supercapacitors. Energy Environ Sci, 2013, 6: 1249-1259

157 Zhang Y, Liu S, Zheng X, et al. Biomass organs control the porosity of their pyrolyzed carbon. Adv Funct Mater, 2017, 27: 1604687

158 Sackur O. Die anwendung hoher drucke bei chemischen vorgängen und eine nachbildung des entstehungsprozesses der steinkohle. Von friedrich bergius. $58 \mathrm{~S}$. und 4 abbildungen. Verlag von wilhelm knapp, halle a. S. 1913. Preis geb. 2,80 MK. Zeitschrift für Elektrochemie und angewandte physikalische Chemie, 1914, 20: 260-260

159 Berl E, Schmidt A. Über die entstehung der kohlen. II. die inkohlung von cellulose und lignin in neutralem medium. Justus Liebigs Ann Chem, 1932, 493: 97-123

160 Fuertes AB, Sevilla M. Superior capacitive performance of hydrochar-based porous carbons in aqueous electrolytes. ChemSusChem, 2015, 8: 1049-1057

161 Zhu H, Wang X, Yang F, et al. Promising carbons for supercapacitors derived from fungi. Adv Mater, 2011, 23: 2745-2748

162 Wei T, Zhang Q, Wei X, et al. A facile and low-cost route to heteroatom doped porous carbon derived from broussonetia $p a-$ pyrifera bark with excellent supercapacitance and $\mathrm{CO}_{2}$ capture performance. Sci Rep, 2016, 6: 22646

163 Manyala N, Bello A, Barzegar F, et al. Coniferous pine biomass: a novel insight into sustainable carbon materials for supercapacitors electrode. Mater Chem Phys, 2016, 182: 139-147

$164 \mathrm{Hu} \mathrm{B}$, Wang K, Wu L, et al. Engineering carbon materials from the hydrothermal carbonization process of biomass. Adv Mater, 2010, 22: 813-828

165 Xue Y, Gao B, Yao Y, et al. Hydrogen peroxide modification enhances the ability of biochar (hydrochar) produced from hydrothermal carbonization of peanut hull to remove aqueous heavy metals: batch and column tests. Chem Eng J, 2012, 200-202: 673-680

166 Parshetti GK, Kent Hoekman S, Balasubramanian R. Chemical, structural and combustion characteristics of carbonaceous products obtained by hydrothermal carbonization of palm empty fruit bunches. Bioresource Tech, 2013, 135: 683-689

167 Liu Z, Zhang FS, Wu J. Characterization and application of chars produced from pinewood pyrolysis and hydrothermal treatment. Fuel, 2010, 89: 510-514

168 Román S, Valente Nabais JM, Ledesma B, et al. Production of low-cost adsorbents with tunable surface chemistry by conjunction of hydrothermal carbonization and activation processes. Microporous Mesoporous Mater, 2013, 165: 127-133

169 Aydıncak K, Yumak T, Sınağ A, et al. Synthesis and characterization of carbonaceous materials from saccharides (glucose and lactose) and two waste biomasses by hydrothermal carbonization. Ind Eng Chem Res, 2012, 51: 9145-9152

170 Sevilla M, Maciá-Agulló JA, Fuertes AB. Hydrothermal carbonization of biomass as a route for the sequestration of $\mathrm{CO}_{2}$ : Chemical and structural properties of the carbonized products. Biomass BioEnergy, 2011, 35: 3152-3159
White RJ, Yoshizawa N, Antonietti M, et al. A sustainable synthesis of nitrogen-doped carbon aerogels. Green Chem, 2011, 13: 2428

172 Titirici MM, Thomas A, Antonietti M. Replication and coating of silica templates by hydrothermal carbonization. Adv Funct Mater, 2007, 17: 1010-1018

173 Jain A, Jayaraman S, Balasubramanian R, et al. Hydrothermal pretreatment for mesoporous carbon synthesis: enhancement of chemical activation. J Mater Chem A, 2014, 2: 520-528

174 Jain A, Balasubramanian R, Srinivasan MP. Hydrothermal conversion of biomass waste to activated carbon with high porosity: a review. Chem Eng J, 2016, 283: 789-805

175 Sun W, Lipka SM, Swartz C, et al. Hemp-derived activated carbons for supercapacitors. Carbon, 2016, 103: 181-192

176 Titirici MM, Antonietti M. Chemistry and materials options of sustainable carbon materials made by hydrothermal carbonization. Chem Soc Rev, 2010, 39: 103-116

177 Thambidurai A, Lourdusamy JK, John JV, et al. Preparation and electrochemical behaviour of biomass based porous carbons as electrodes for supercapacitors-a comparative investigation. Korean J Chem Eng, 2014, 31: 268-275

178 Sudhan N, Subramani K, Karnan M, et al. Biomass-derived activated porous carbon from rice straw for a high-energy symmetric supercapacitor in aqueous and non-aqueous electrolytes. Energy Fuels, 2017, 31: 977-985

179 Ma G, Hua F, Sun K, et al. Porous carbon derived from sorghum stalk for symmetric supercapacitors. RSC Adv, 2016, 6: 103508103516

180 Huang C, Sun T, Hulicova-Jurcakova D. Wide electrochemical window of supercapacitors from coffee bean-derived phosphorusrich carbons. ChemSusChem, 2013, 6: 2330-2339

181 Gharehkhani S, Seyed Shirazi SF, Pilban Jahromi S, et al. Spongy nitrogen-doped activated carbonaceous hybrid derived from biomass material/graphene oxide for supercapacitor electrodes. RSC Adv, 2015, 5: 40505-40513

182 Genovese M, Lian K. Polyoxometalate modified pine cone biochar carbon for supercapacitor electrodes. J Mater Chem A, 2017, 5: 3939-3947

183 Jiang M, Zhang J, Xing L, et al. KOH-activated porous carbons derived from chestnut shell with superior capacitive performance. Chin J Chem, 2016, 34: 1093-1102

184 Redondo E, Carretero-González J, Goikolea E, et al. Effect of pore texture on performance of activated carbon supercapacitor electrodes derived from olive pits. Electrochim Acta, 2015, 160: 178184

185 Misnon II, Zain NKM, Aziz RA, et al. Electrochemical properties of carbon from oil palm kernel shell for high performance supercapacitors. Electrochim Acta, 2015, 174: 78-86

186 Deng L, Zhong W, Wang J, et al. The enhancement of electrochemical capacitance of biomass-carbon by pyrolysis of extracted nanofibers. Electrochim Acta, 2017, 228: 398-406

187 Yadav P, Basu A, Suryawanshi A, et al. Highly stable laser-scribed flexible planar microsupercapacitor using mushroom derived carbon electrodes. Adv Mater Interfaces, 2016, 3: 1600057

188 Wang $\mathrm{K}, \mathrm{Xu} \mathrm{M}, \mathrm{Gu} \mathrm{Z}$, et al. Pyrrole modified biomass derived hierarchical porous carbon as high performance symmetrical supercapacitor electrodes. Int J Hydrogen Energy, 2016, 41: 13109-13115

189 Zhan C, Yu X, Liang Q, et al. Flour food waste derived activated carbon for high-performance supercapacitors. RSC Adv, 2016, 6: 89391-89396 
190 Boyjoo Y, Cheng Y, Zhong H, et al. From waste Coca Cola to activated carbons with impressive capabilities for $\mathrm{CO}_{2}$ adsorption and supercapacitors. Carbon, 2017, 116: 490-499

191 Luan Y, Huang Y, Wang L, et al. Porous carbon@ $\mathrm{MnO}_{2}$ and nitrogen-doped porous carbon from carbonized loofah sponge for asymmetric supercapacitor with high energy and power density. J Electroanal Chem, 2016, 763: 90-96

192 Chen C, Zhang Y, Li Y, et al. All-wood, low tortuosity, aqueous, biodegradable supercapacitors with ultra-high capacitance. Energy Environ Sci, 2017, 10: 538-545

193 Wu S, Zhu Y. Highly densified carbon electrode materials towards practical supercapacitor devices. Sci China Mater, 2016, 60: 25-38

194 Mullaivananathan V, Sathish R, Kalaiselvi N. Coir pith derived bio-carbon: demonstration of potential anode behavior in lithium-ion batteries. Electrochim Acta, 2017, 225: 143-150

195 Zhu C, Akiyama T. Cotton derived porous carbon via an $\mathrm{MgO}$ template method for high performance lithium ion battery anodes. Green Chem, 2016, 18: 2106-2114

196 Ru H, Xiang K, Zhou W, et al. Bean-dreg-derived carbon materials used as superior anode material for lithium-ion batteries. Electrochim Acta, 2016, 222: 551-560

$197 \mathrm{Ru} \mathrm{H}$, Bai N, Xiang K, et al. Porous carbons derived from microalgae with enhanced electrochemical performance for lithiumion batteries. Electrochim Acta, 2016, 194: 10-16

198 Liu T, Kavian R, Chen Z, et al. Biomass-derived carbonaceous positive electrodes for sustainable lithium-ion storage. Nanoscale, 2016, 8: 3671-3677

199 Yu X, Zhang K, Tian N, et al. Biomass carbon derived from sisal fiber as anode material for lithium-ion batteries. Mater Lett, 2015, 142: 193-196

200 Han SW, Jung DW, Jeong JH, et al. Effect of pyrolysis temperature on carbon obtained from green tea biomass for superior lithium ion battery anodes. Chem Eng J, 2014, 254: 597-604

201 Wang SX, Yang L, Stubbs LP, et al. Lignin-derived fused electrospun carbon fibrous mats as high performance anode materials for lithium ion batteries. ACS Appl Mater Interfaces, 2013, 5: $12275-12282$

202 Mondal AK, Kretschmer K, Zhao Y, et al. Naturally nitrogen doped porous carbon derived from waste shrimp shells for highperformance lithium ion batteries and supercapacitors. Microporous Mesoporous Mater, 2017, 246: 72-80

203 Ou J, Yang L, Xi X. Biomass inspired nitrogen doped porous carbon anode with high performance for lithium ion batteries. Chin J Chem, 2016, 34: 727-732

204 Ou J, Zhang Y, Chen L, et al. Nitrogen-rich porous carbon derived from biomass as a high performance anode material for lithium ion batteries. J Mater Chem A, 2015, 3: 6534-6541

205 Ou J, Zhang Y, Chen L, et al. Heteroatom doped porous carbon derived from hair as an anode with high performance for lithium ion batteries. RSC Adv, 2014, 4: 63784-63791

206 Chen L, Zhang Y, Lin C, et al. Hierarchically porous nitrogen-rich carbon derived from wheat straw as an ultra-high-rate anode for lithium ion batteries. J Mater Chem A, 2014, 2: 9684-9690

207 Wang L, Xue J, Gao B, et al. Rice husk derived carbon-silica composites as anodes for lithium ion batteries. RSC Adv, 2014, 4:

\section{4-64746}

208 Che Y, Zhu X, Li J, et al. Simple synthesis of $\mathrm{MoO}_{2} /$ carbon aerogel anodes for high performance lithium ion batteries from seaweed biomass. RSC Adv, 2016, 6: 106230-106236

$209 \mathrm{Wu}$ J, Zuo L, Song Y, et al. Preparation of biomass-derived hierarchically porous carbon $/ \mathrm{Co}_{3} \mathrm{O}_{4}$ nanocomposites as anode materials for lithium-ion batteries. J Alloys Compd, 2016, 656: $745-752$

210 Lu Y, Fong E. Biomass-mediated synthesis of carbon-supported nanostructured metal sulfides for ultra-high performance lithium-ion batteries. J Mater Chem A, 2016, 4: 2738-2745

211 Chen J, Liu W, Liu S, et al. Marine microalgaes-derived porous $\mathrm{ZnMn}_{2} \mathrm{O}_{4} / \mathrm{C}$ microspheres and performance evaluation as Li-ion battery anode by using different binders. Chem Eng J, 2017, 308: 1200-1208

212 Bongu CS, Karuppiah S, Nallathamby K. Validation of green composite containing nanocrystalline $\mathrm{Mn}_{2} \mathrm{O}_{3}$ and biocarbon derived from human hair as a potential anode for lithium-ion batteries. J Mater Chem A, 2015, 3: 23981-23989

213 Cheng F, Li WC, Lu AH. Interconnected nanoflake network derived from a natural resource for high-performance lithium-ion batteries. ACS Appl Mater Interfaces, 2016, 8: 27843-27849

214 Xia Y, Zhang W, Xiao Z, et al. Biotemplated fabrication of hierarchically porous $\mathrm{NiO} / \mathrm{C}$ composite from lotus pollen grains for lithium-ion batteries. J Mater Chem, 2012, 22: 9209-9215

215 Liu P, Li Y, Hu YS, et al. A waste biomass derived hard carbon as a high-performance anode material for sodium-ion batteries. J Mater Chem A, 2016, 4: 13046-13052

216 Ou J, Yang L, Xi X. Hierarchical porous nitrogen doped carbon derived from horn comb as anode for sodium-ion storage with high performance. Electron Mater Lett, 2016, 13: 66-71

217 Yang T, Niu X, Qian T, et al. Half and full sodium-ion batteries based on maize with high-loading density and long-cycle life. Nanoscale, 2016, 8: 15497-15504

218 Zhang F, Yao Y, Wan J, et al. High temperature carbonized grass as a high performance sodium ion battery anode. ACS Appl Mater Interfaces, 2017, 9: 391-397

219 Zhang X, Li P, Zang R, et al. Antimony/porous biomass carbon nanocomposites as high-capacity anode materials for sodium-ion batteries. Chem Asian J, 2017, 12: 116-121

220 Dahbi M, Kiso M, Kubota K, et al. Synthesis of hard carbon from argan shells for Na-ion batteries. J Mater Chem A, 2017, 5: 99179928

Acknowledgements This work was supported by the National Natural Science Foundation of China (51702117, 51672055), Major Research Projects Fund of Jilin Institute of Chemical Technology (2016006), Natural Science Foundation of Heilongjiang Province of China (E201416).

Author contributions Jiang L and Sheng L searched the reference and wrote the paper. Fan $\mathrm{Z}$ designed the outlines and modified the manuscript. All authors contributed to the general discussion.

Conflict of interest The authors declare that they have no conflict of interest. 


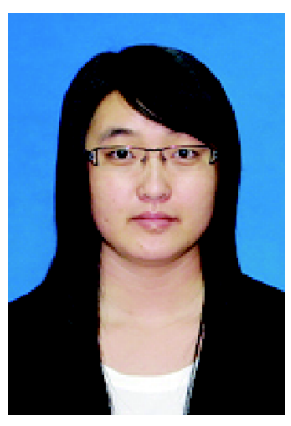

Lili Jiang received her $\mathrm{PhD}$ degree in 2016 at the College of Materials Science and Chemical Engineering at Harbin Engineering University. She is now an associate professor at Jilin Institute of Chemical Technology. Her current research is focused on the design and synthesis of functional carbonaceous nanomaterials as well as their applications for energy conversion and storage devices.

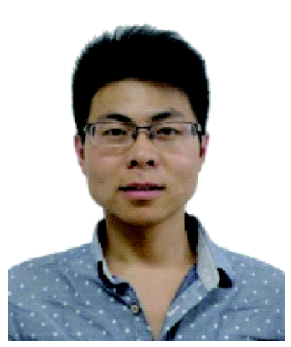

Lizhi Sheng currently is pursuing PhD degree in the College of Materials Science and Chemical Engineering at Harbin Engineering University. His research interests mainly focus on the design and synthesis of functional carbonaceous nanomaterials and their applications for energy storage.

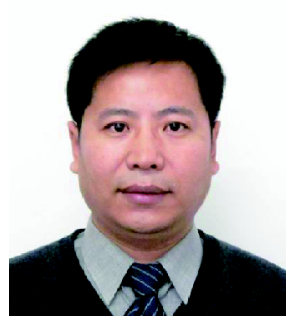

Zhuangjun Fan received his PhD in 2003 at the Institute of Coal Chemistry, Chinese Academy of Sciences. He became full professor at the College of Materials Science and Chemical Engineering in 2006, and now he is the director of the Institue of Advanced Carbon Based Materials at Harbin Engineering University. His research interests focus on the design and controlled synthesis of carbon nanomaterials such as carbon nanotubes and graphene, and their applications in energy-related areas such as supercapacitors, Li ion batteries and full cells.

\section{生物质衍生碳材料的结构多样性及其在能量存储方面的应用}

江丽丽 ${ }^{1,2}$, 盛利志 ${ }^{2}$, 范壮军 ${ }^{2 *}$

摘要 目前, 碳材料依靠其自身结构和功能的多样性, 已成功地应用于能源储存领域. 先进科学与技术的发展促使我们对绿色和可持续的 储能材料需求越来越迫切, 生物质衍生碳因其结构的多样性、可调节的物理/化学性质、环境友好和价格低廉而引起人们的广泛关注. 由 于自然界赋予生物质奇异的微观结构, 导致其衍生碳材料也显示出结构多样性, 如零维的球形、一维的纤维、二维的片层和三维的空间 结构. 本综述介绍了生物质衍生碳材料的结构多样性, 多孔特性, 表面改性和杂原子掺杂, 及其在超级电容器、锂离子电池和钠离子电池 中的应用, 并提出未来发展的趋势和挑战. 